\title{
Effects of energetic electrons on the electrodynamics in the ionosphere
}

\author{
A. Aksnes ${ }^{1}$, J. Stadsnes ${ }^{1}$, G. Lu ${ }^{2}$, N. Østgaard ${ }^{3}$, R. R. Vondrak $^{4}$, D. L. Detrick ${ }^{5}$, T. J. Rosenberg ${ }^{5}$, G. A. Germany ${ }^{6}$, \\ and M. Schulz ${ }^{7}$ \\ ${ }^{1}$ Department of Physics, University of Bergen, Bergen, Norway \\ ${ }^{2}$ High Altitude Observatory/National Center of Atmospheric Research, 3450 Mitchell Lane, Boulder, CO 80301, USA \\ ${ }^{3}$ University of California, Berkeley, CA 94720-7450, USA \\ ${ }^{4}$ NASA/Goddard Space Flight Center, Greenbelt, MD 20771, USA \\ ${ }^{5}$ University of Maryland, College Park, MD 20742, USA \\ ${ }^{6}$ University of Alabama in Huntsville, AL 35899, USA \\ ${ }^{7}$ Lockheed Martin Advanced Technology Center, 3251 Hanover Street, Palo Alto, CA 94304, USA
}

Received: 21 March 2003 - Revised: 13 June 2003 - Accepted: 2 July 2003 - Published: 1 January 2004

\begin{abstract}
From the observations by the PIXIE and UVI cameras on board the Polar satellite, we derive global maps of the precipitating electron energy spectra from less than $1 \mathrm{keV}$ to $100 \mathrm{keV}$. Based on the electron spectra, we generate instantaneous global maps of Hall and Pedersen conductances. The UVI camera provides good coverage of the lower electron energies contributing most to the Pedersen conductance, while PIXIE captures the high energy component of the precipitating electrons affecting the Hall conductance. By characterizing the energetic electrons from some tens of $\mathrm{keV}$ and up to about $100 \mathrm{keV}$ using PIXIE X-ray measurements, we will, in most cases, calculate a larger electron flux at higher energies than estimated from a simple extrapolation of derived electron spectra from UVI alone. Instantaneous global conductance maps derived with and without inclusion of PIXIE data have been implemented in the Assimilative Mapping of Ionospheric Electrodynamics (AMIE) procedure, to study the effects of energetic electrons on electrodynamical parameters in the ionosphere. We find that the improved electron spectral characterization using PIXIE data most often results in a larger Hall conductance and a smaller inferred electric field. In some localized regions the increase in the Hall conductance can exceed $100 \%$. On the contrary, the Pedersen conductance remains more or less unaffected by the inclusion of the PIXIE data. The calculated polar cap potential drop may decrease more than $10 \%$, resulting in a reduction of the estimated Joule heating integrated over the Northern Hemisphere by up to $20 \%$. Locally, Joule heating may decrease more than $50 \%$ in some regions. We also find that the calculated energy flux by precipitating electrons increases around 5\% when including the PIXIE data. Combined with the reduction of Joule heating, this results in a decrease in the ratio between Joule heating and energy flux, sometimes exceeding $25 \%$. An investigation of the relationship between Joule heating and the $A E$ index shows a nearly
\end{abstract}

Correspondence to: A. Aksnes (Arve.Aksnes@ fi.uib.no) linear correspondence between the two quantities, in accordance with previous studies. However, we find lower proportionality factors than reported by others when taking geomagnetic conditions into account, ranging between 0.13 and $0.23 \mathrm{GW} / \mathrm{nT}$. We also find that the contribution from auroral particles to the energy budget is more important than most previous studies have reported.

Key words. Ionosphere (auroral ionosphere; particle precipitation) - Magnetospheric physics (storms and substorms)

\section{Introduction}

An auroral substorm is one of the most striking features we know, as it often results in bright and beautiful aurora in the sky. However, it is also a significant phenomena, because of its relationship to magnetospheric dynamics. Understanding the electrodynamics in the ionosphere is crucial to improving our understanding of magnetosphere-ionosphere coupling. Developing this understanding is greatly complicated by the fact that the electrodynamic behavior changes drastically during auroral substorms.

In order to gain more knowledge about the processes that couple the different regions in the near-Earth environment, we need to know how the electrodynamics in the ionosphere vary during a substorm and how the different parameters relate to each other. The Assimilative Mapping of Ionospheric Electrodynamics (AMIE) procedure is a tool to understand the electrodynamics, as this technique provides global instantaneous distributions of ionospheric electrodynamical parameters.

In a statistical study Østgaard et al. (1999) investigated the global features of the aurora using X-ray measurements from the Polar Ionospheric X-ray Imaging Experiment (PIXIE) and ultraviolet emissions from the Ultraviolet Imager (UVI) on board the Polar satellite. They studied 14 isolated sub- 
storm events from 1996, and they found significant changes between the particle precipitation detected by the UVI and PIXIE cameras. The growth phase was found to be dominated by lower electron energies less than $10 \mathrm{keV}$, well measured by UVI. As the expansion phase took place, UVI data showed intense precipitation in the duskward part of the auroral bulge. PIXIE, on the other hand, revealed an eastward drift of the X-ray aurora. During the recovery phase, PIXIE showed a precipitation maximum in the morning sector which was not seen by UVI. Many studies have reported such a maximum in the energetic electron precipitation in the dawn region, including substorm studies (Jelly and Brice, 1967; Berkey et al., 1974; Østgaard et al., 2001; Aksnes et al., 2002) and statistical studies involving different geomagnetic conditions (Hartz and Brice, 1967; McDiarmid et al., 1975; Wallis and Budzinski, 1981; Spiro et al., 1982; Hardy et al., 1985; Hardy et al., 1987). Østgaard et al. (1999) used models of the gradient and curvature drift of electrons to estimate the energy of eastward drifting electrons causing the $\mathrm{X}$-rays seen by PIXIE. Their result indicated average electron energies usually within 90 and $120 \mathrm{keV}$, though one particular event actually revealed an electron energy between 180 and $200 \mathrm{keV}$. Such energetic electrons during substorms are in accordance with X-ray studies by Sletten et al. (1971) and Kangas et al. (1975).

The electron density is critical for determining the ionospheric conductivities (Chapman, 1956), meaning that the Hall and Pedersen conductivities can be strongly affected by electron precipitation. A study by Aksnes et al. (2002) showed that the calculation of an accurate Hall conductance depends strongly on measurements of energetic electrons up to $100 \mathrm{keV}$. Aksnes et al. (2002) also used Polar data from the PIXIE and UVI cameras, in order to provide instantaneous global conductance maps. By calculating the conductivities from combined PIXIE and UVI measurements, to compare with the conductivities from using UVI data only, they found significant differences in the Hall conductance. In some regions, the Hall conductance increased by almost $50 \%$ when including the energetic electrons estimated from the PIXIE measurements. On the contrary, the Pedersen conductance was hardly affected at all. This is explained by the fact that the largest Pedersen and Hall conductivities are occurring in different height regions. Electrons with energies in the range of a few $\mathrm{keV}$ will deposit their energy around $125 \mathrm{~km}$ (Rees, 1963), where the Pedersen conductivity peaks. Higher electron energies will penetrate further down in the ionosphere, contributing more to the Hall conductivity. The highest values of the Hall conductivity are found below $110 \mathrm{~km}$, where the ions are strongly coupled to the neutrals.

The intensity of the shortest UVI-wavelengths decreases strongly at higher electron energies (Lummerzheim et al., 1991; Germany et al., 1990; 1998b), so UVI measurements are unable to accurately characterize the most energetic electrons. Several papers have shown that the electron energy spectrum often changes and becomes harder at higher energies, meaning that the slope of the spectrum flattens out (Meng et al., 1979; Goldberg et al., 1982; Miller and Von- drak, 1985; Østgaard et al., 2000). Therefore it is not sufficient to simply extrapolate the UVI derived electron energy spectra in order to take the higher electron energies into account. The improved electron spectral characterization at higher energies using PIXIE data may sometimes result in a lower electron flux than calculated from extrapolated UVI derived electron spectra. As we will see in this study, however, the most likely situation when including PIXIE data to characterize the precipitating electrons is a significantly larger flux at higher electron energies.

In this paper the AMIE procedure is used for the first time to study the effects of energetic electrons on the electrodynamics in the ionosphere. The term "energetic electrons" refers to the electrons from approximately $20 \mathrm{keV}$ up to about $100 \mathrm{keV}$, estimated from the PIXIE measurements responsible for a hardening of the spectra compared to the extrapolated UVI spectra. The technique used to calculate the conductances from the PIXIE and UVI data is described in Sect. 2, while Sect. 3 gives a brief overview of the AMIE procedure and the method and data sets used for this study. Results are presented in Sect. 4 and discussed in Sect. 5. Finally, we summarize and conclude in Sect. 6.

\section{Deriving ionospheric conductances from $\mathrm{X}$-rays and UV-emissions}

Data from the PIXIE and UVI cameras are used to obtain global instantaneous ionospheric Hall and Pedersen conductances. We present in this section the methodology used to deduce the conductances.

2.1 Deriving electron energy spectra from the PIXIE measurements

Bremsstrahlung is produced when precipitating electrons interact with the nuclei of atmospheric particles to form a continuous spectrum of X-rays. X-ray photons between approximately 2 and $22 \mathrm{keV}$ were measured by the pinhole camera PIXIE on Polar (Imhof et al., 1995).

From neutron transport codes (Lorence, 1992), a coupled electron photon transport code has been developed. This has resulted in a look-up table giving the production emitted at different zenith angles for electrons with different exponential energy spectra. By using this look-up table, we are able to derive a four-parameter representation of the electron spectral distribution causing the measured X-rays (see Østgaard et al., 2000, for more details).

2.2 Deriving electron energy spectra from the UVI measurements

UV-emissions are produced by the electrons precipitating in the atmosphere. Protons can also contribute to the UVemissions (Frey et al., 2001). This may cause uncertainties in the estimation of conductivities, which we will discuss in more detail in Sect. 5.2. 
The UVI instrument (Torr et al., 1995) provides global images of emissions within the Lyman-Birge-Hopfield (LBH) band $(140-180 \mathrm{~nm})$. Within this emission band, the $\mathrm{O}_{2}$ absorption differs significantly, as the $\mathrm{O}_{2}$ Schumann-Runge absorption continuum peaks at the shorter wavelengths and decreases with longer wavelengths. The UV-emissions have been separated into LBHS (140-160 nm) and LBHL (160$180 \mathrm{~nm}$ ), where $\mathrm{S}$ and $\mathrm{L}$ refer to short and long wavelengths, respectively. By taking the ratio between the intensities of the two LBH-bands, we are able to derive the average electron energy, as the shorter wavelengths (LBHS) are subject to significantly greater $\mathrm{O}_{2}$ absorption than the longer wavelengths (LBHL). The intensity of the LBHL emissions are further used to calculate the electron energy flux. A more detailed description is given by Germany et al. (1997, 1998a, b).

\subsection{Deriving electron energy spectra from both PIXIE and UVI measurements}

We combine derived energy spectra from PIXIE and UVI, in order to estimate a more reliable spectrum having an electron energy range between approximately 0.1 and $100 \mathrm{keV}$ (Østgaard et al., 2001). Since the production of X-ray photons is low, we need to include measurements from an extensive area or to increase the time averaging, in order to obtain count rates that are statistically significant to derive a proper electron spectrum. The spatial resolution of the PIXIE camera is rather coarse, varying between 600 and $900 \mathrm{~km}$ at a distance $6-8 R_{E}$ from the Earth. By dividing the measurements into boxes of $6^{\circ}$ in corrected geomagnetic (CGM) latitude by $1 \mathrm{~h}$ in magnetic local time (MLT) (Østgaard et al., 2001), we derive the energy spectra from a region comparable in size with the spatial resolution of PIXIE. The first box is between CGM latitudes 52 and $58^{\circ}$, and the last box is situated at CGM latitudes $76-82^{\circ}$. Due to a high voltage problem, a duty cycling scheme is applied, meaning that one of the detecting chambers of PIXIE is on $4.5 \mathrm{~min}$ and then off for some minutes. In this paper, we will present data for a substorm event occurring on 26 June 1998, when the chamber is off for $5.5 \mathrm{~min}$, leaving us with images of $4.5 \mathrm{~min}$ exposure every $10 \mathrm{~min}$. We will also study the electrodynamics during two other substorm events from 1997, when we have images every $15 \mathrm{~min}$. The UVI camera has a much better time resolution than the PIXIE instrument. It takes on the order of two minutes, dependent on operating mode, to accumulate the two LBH images needed to perform an electron energy spectrum analysis. The spatial resolution is also much better for the UVI instrument, though the wobbling of the Polar satellite considerably degrades the resolution in one direction. From apogee the spatial resolution is approximately $40 \mathrm{~km} \times 360 \mathrm{~km}$. In order to combine the measurements from PIXIE and UVI, we average UVI pixels contained within the boxes of $6^{\circ}$ in CGM latitude by $1 \mathrm{~h}$ in MLT and within the exposure time of the PIXIE measurements.
From the X-ray measurements, we derive a four-parameter exponential electron spectrum. From the UV-emission data, we estimate an average electron energy, as well as an energy flux. These data are used to fit an exponential and a Maxwellian distribution. We then choose the spectrum which gives the smoothest transition to the exponential electron spectrum derived from the PIXIE data.

\subsection{Deriving conductance values from the energy spectra}

The University of Maryland has developed a computer code to model the ionospheric effects of energy deposition by precipitating particles. Their computer code is based on the TANGLE code (Vondrak and Baron, 1976; Vondrak and Robinson, 1985). By giving the electron spectra derived from the PIXIE and UVI measurements as input, this code can estimate the conductivities. As a first step, the electron production rate $q$ is calculated. This process involves a model of the atmosphere, and the code uses a set of values for neutral density, composition and temperature which are comparable with the Mass Spectrometer and Incoherent Scatter Extended Atmospheric model (MSIS-E-90). We also need a deposition function of the electron energy, which is set to be the cosinedependent Isotropic over the Downward Hemisphere (IDH) model of Rees (1963). After calculating the electron production rate $q$, the code establishes a value of the electron density $N_{e}$ from the time-dependent rate equation:

$d N_{e} / d t=q(h)-\alpha_{\mathrm{eff}}(h) * N_{e}^{2}(h)$.

Diffusive transport is negligible at the heights contributing to the conductances and is therefore not included in Eq. (1). The effective dissociative recombination coefficient $\alpha_{\text {eff }}$ is calculated by using formulas derived from Vickrey et al. (1982) and Gledhill (1986). As the recombination time is of the order of seconds, we assume chemical equilibrium and set $d N_{e} / d t=0$. By using electron-neutral collision frequencies from Thrane and Piggott (1966), as well as ion-neutral collision frequencies from Vickrey et al. (1981), the conductivities are derived.

\subsection{Limitations in the technique used to derive the iono- spheric conductances from PIXIE and UVI measure- ments}

The rather coarse PIXIE resolution (600-900 km) means that we cannot resolve localized enhancements in the energetic electron flux. Therefore, the strongest Hall conductance values derived using PIXIE X-ray measurements seldom exceed 50 S. In comparison, Gjerloev and Hoffman (2000) were able to identify much larger Hall conductance peaks of more than $100 \mathrm{~S}$ using electron precipitation data from the Dynamic Explorer (DE) 2 satellite. These values were reported to be highly localized, with a scale size of typically $20 \mathrm{~km}$. Similar results showing maximum values of about $90 \mathrm{~S}$ were found by Marklund et al. (1982), using particle data obtained by the S23L1 rocket crossing over a discrete pre-breakup arc in January 1979. Kirkwood et al. (1988) calculated Hall con- 
ductance values reaching $120 \mathrm{~S}$, using electron density profiles with high resolution in both altitude $(2 \mathrm{~km})$ and time (5 s) obtained from the European Incoherent Scatter (EISCAT) radar. Aikio and Kaila (1996) also made use of EISCAT data and determined an extreme value of $214 \mathrm{~S}$. Morelli et al. (1995) combined measurements of the line-of-sight (LOS) Doppler velocity from the PACE HF radar located in Antarctica with conjugate magnetic observations on the Greenland west meridian chain, to estimate the Hall conductance. Despite the large uncertainty, as the data compared were taken from different hemispheres, it is interesting to note that the results found by Morelli et al. for a multipleonset substorm on 12 April 1988, indicate Hall conductances of $\sim 80-160 \mathrm{~S}$. The inability to identify localized structures using PIXIE measurements means that the electron flux at higher energies is being smoothed over a broad region. This implies that the effects of energetic electrons to be presented in this study should be even more significant and much larger in localized regions with strong gradients in the precipitation.

Another issue is the estimation of electron spectra from UVI and PIXIE data. As explained in Sects. 2.1-2.3, this procedure is not straightforward, as the precipitating electrons are derived indirectly from measurements of UVemissions and X-ray photons. For the low electron energy range based on UV-emissions, Germany et al. (2001) performed a sensitivity study and estimated an upper limit of $23 \%$ for modelling errors when calculating mean energies. Non-modelling errors, such as imaging processing and Poisson uncertainties, were estimated by Germany et al. (1997; $1998 \mathrm{a} ; 1998 \mathrm{~b})$ to be 3 and $5 \%$, respectively. In a study, where both UVI and PIXIE measurements were used to derive the electron spectra in the energy range from $0.1 \mathrm{keV}$ to $100 \mathrm{keV}$, Østgaard et al. (2001) found the derived electron energy flux to be in fairly good agreement with in situ particle measurements from the Defense Meteorological Satellite Program (DMSP) spacecraft. An average ratio of 1.03 \pm 0.6 was found between the measured and derived energy flux between $90 \mathrm{eV}$ and $30 \mathrm{keV}$. Note that the large standard deviation is caused by the different spatial resolutions. The electron fluxes measured along the trajectory by a polar orbiting satellite are not necessarily the same as the average electron flux in the corresponding PIXIE pixel.

\section{The AMIE procedure}

The AMIE procedure is an optimally constrained, weighted, least-squares fitting of coefficients to measurements of different electrodynamical quantities. The purpose of AMIE is to obtain the best possible estimate of the electrodynamics in the ionosphere by combining available observations of electrodynamical parameters. AMIE uses apex coordinates (VanZandt et al., 1972; Richmond, 1995) and has a grid size of about $1.7^{\circ}$ in latitude and $10^{\circ}$ in longitude. The AMIE procedure is described in detail by Richmond and Kamide ‘(1988) and Richmond (1992). We will only give a brief overview below.

\subsection{Ionospheric electrodynamics derived from AMIE}

AMIE first estimates Hall and Pedersen conductances by using observational data to modify a statistical conductance model. This includes, for example, satellite measurements of precipitating particles through empirical formulas by Robinson et al. (1987) involving energy flux and mean energy. Magnetic perturbations observed at the Earth's surface are further used to modify the conductance pattern (Ahn et al., 1983a). Through formulas by Kroehl (Kroehl, personal communication, 1991) the solar-induced conductances, depending on the solar zenith angle and the F10.7 flux value, are also incorporated in the AMIE procedure. By combining all available data and assuming that the modified conductances ideally represent the true conductances, AMIE estimates the electric convection patterns. In this process the different data sets are weighted according to their errors, so that the most reliable data will contribute most to the fitting. A statistical convection model is incorporated in regions where no in situ measurements exist. After establishing the conductance and the convection patterns, AMIE then provides distributions of electrodynamical parameters, such as Joule heating $\Sigma_{P} E^{2}$, height-integrated electric currents $J_{\perp}$ and field-aligned currents $-\nabla \cdot J_{\perp}$. Note that the effects of neutral wind are neglected in AMIE, as it is difficult to obtain a realistic wind pattern.

\subsection{Data and method used in this study}

The electrodynamical parameters derived from AMIE rely strongly upon the conductance patterns established. In this study, we make use of instantaneous global conductance maps derived from PIXIE and UVI measurements. As pointed out in Sect. 1., we need to include the precipitating electrons up to $\sim 100 \mathrm{keV}$ as estimated from the PIXIE data, in order to derive a more accurate Hall conductance. Effects of energetic electrons on the electrodynamics have been investigated by running AMIE using two different sets of conductances calculated with and without the use of the PIXIE data. To study the largest possible effects, we have limited the set of data to include ionospheric conductivity from PIXIE and UVI data and surface magnetic field measurements from ground-based magnetometers. The statistical conductance model of Fuller-Rowell and Evans (1987) and the statistical convection model of Millstone Hill (Foster et al., 1986) are implemented in AMIE in regions not covered by real measurements.

Three periods with substorm activity from 31 July and 28 August 1997, and 26 June 1998, have been investigated, when the Polar satellite was at apogee over the Northern Hemisphere. During these events, data from approximately 140 magnetometer stations have been included in the AMIEcalculations, of which about 65 of these were located in the high-latitude Northern Hemisphere. Note that PIXIE usually has a larger field of view than UVI. In order to perform a proper investigation of the effects of energetic electrons, 


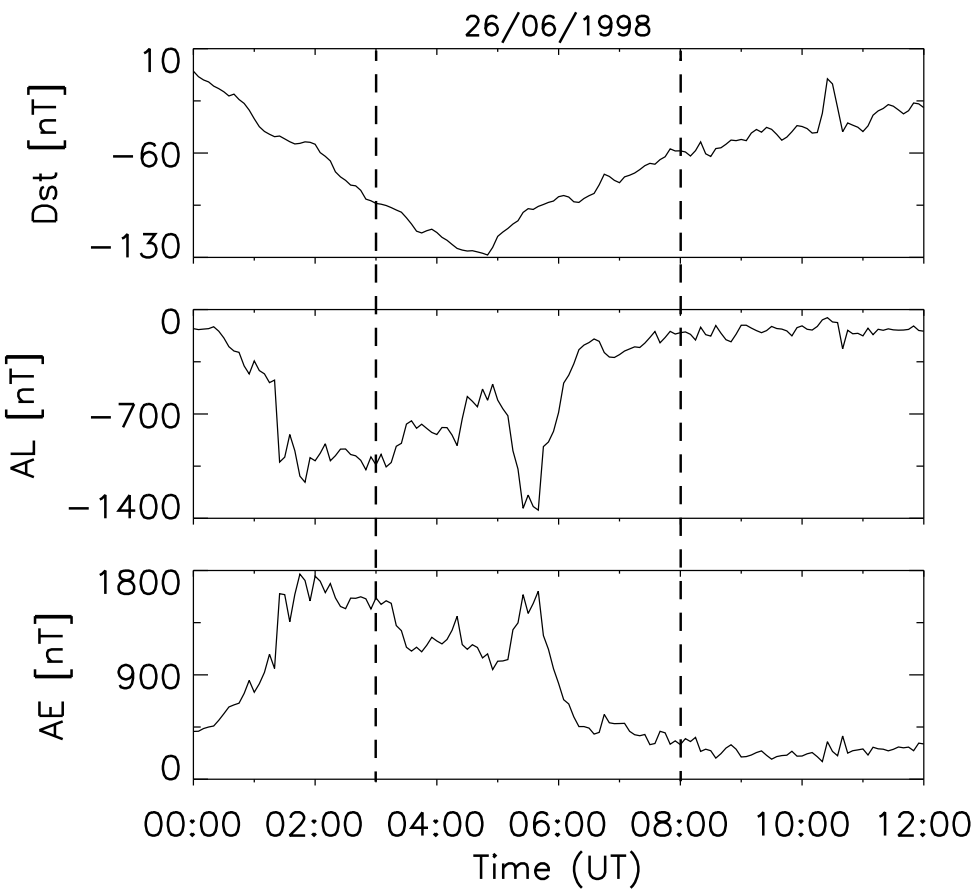

Fig. 1. The $A E, A L$ and $D_{s t}$-indices between 00:00 and 12:00 UT on 26 June 1998. $A E$ and $A L$ are calculated from 63 stations between 55 and $76^{\circ}$ in magnetic latitudes. $D_{s t}$ is calculated from 24 stations below $40^{\circ}$ in magnetic latitudes. The two vertical dashed lines indicate our time interval with data between 03:00 and 08:00 UT.

we have excluded the PIXIE measurements from regions not covered by UVI.

\section{Results}

\subsection{June 1998}

The geomagnetic indices $A E(63), A L(63)$ and $D_{s t}(24)$ are presented in Fig. 1, showing very disturbed conditions during the early part of this day. Note that the numbers in the parenthesis of 63 and 24, respectively, indicate the number of magnetometer stations included in the calculation of the indices. We have measurements from PIXIE and UVI between 03:00 and 08:00 UT, as indicated by the two vertical dashed lines. The main phase of a geomagnetic storm lasted until 04:50 UT, when the $D_{s t}(24)$ index reached a minimum of $-128 \mathrm{nT}$ and thus, is classified as an intense storm (Gonzalez et al., 1994). At the beginning of the recovery phase, a substorm event took place with the magnitude of the $A E(63)$ and the $A L(63)$ indices at 05:40 UT exceeding 1600 and $-1300 \mathrm{nT}$, respectively.

In Fig. 2 we present global maps of the Hall conductance $\Sigma_{H}$ derived during the time period between 05:30 and 06:00 UT on 26 June 1998. The images are $10 \mathrm{~min}$ apart, with an integration time of about $4.5 \mathrm{~min}$ and the middle time as indicated on top of each column. The upper row contains the distribution of the Hall conductance calculated with the AMIE procedure by using magnetometer data and the UVI measurements. In the middle row, the PIXIE data have also been included in the calculation of Hall conductance. We note that the values of Hall conductance are significantly higher when we make use of the PIXIE data, as the improved spectral characterization of the most energetic electrons has resulted in a larger flux at higher electron energies. This is clearly illustrated by the images in the bottom row, which show the local differences in percent when we take into account the energetic electrons from the PIXIE measurements. We find that the differences in Hall conductance can exceed $60 \%$ in some regions when including the PIXIE data. It should be noted, though, that some of the largest differences are found in regions where the Hall conductance values are relatively low. The Pedersen conductance $\Sigma_{P}$ remains more or less unaffected by the increased electron flux at larger energies, as shown in Fig. 3. By comparing global maps of the Pedersen conductance without the PIXIE data (upper row) with the ones that includes the PIXIE measurements (middle row) for the same time interval, as presented in Fig. 2, we hardly see any difference at all. The images in the bottom row showing the differences in percent tell us that the local variations are generally less than $5 \%$.

In Fig. 4, we present the distributions of electric potential during the same 3 successive time periods, as in Fig. 2 and Fig. 3. The black lines represent the electric potential pattern when we have not included PIXIE data, while the red lines show the situation after taking into account the energetic electrons. We note that the general configuration of the patterns remains the same. However, the potential contours shift as the estimated electric field values decrease in regions where the PIXIE data have resulted in a higher Hall conductance. We observe that the lines more or less overlap around noon, consistent with the fact that the images in the bottom row of Fig. 2 show negligible differences in this region when 


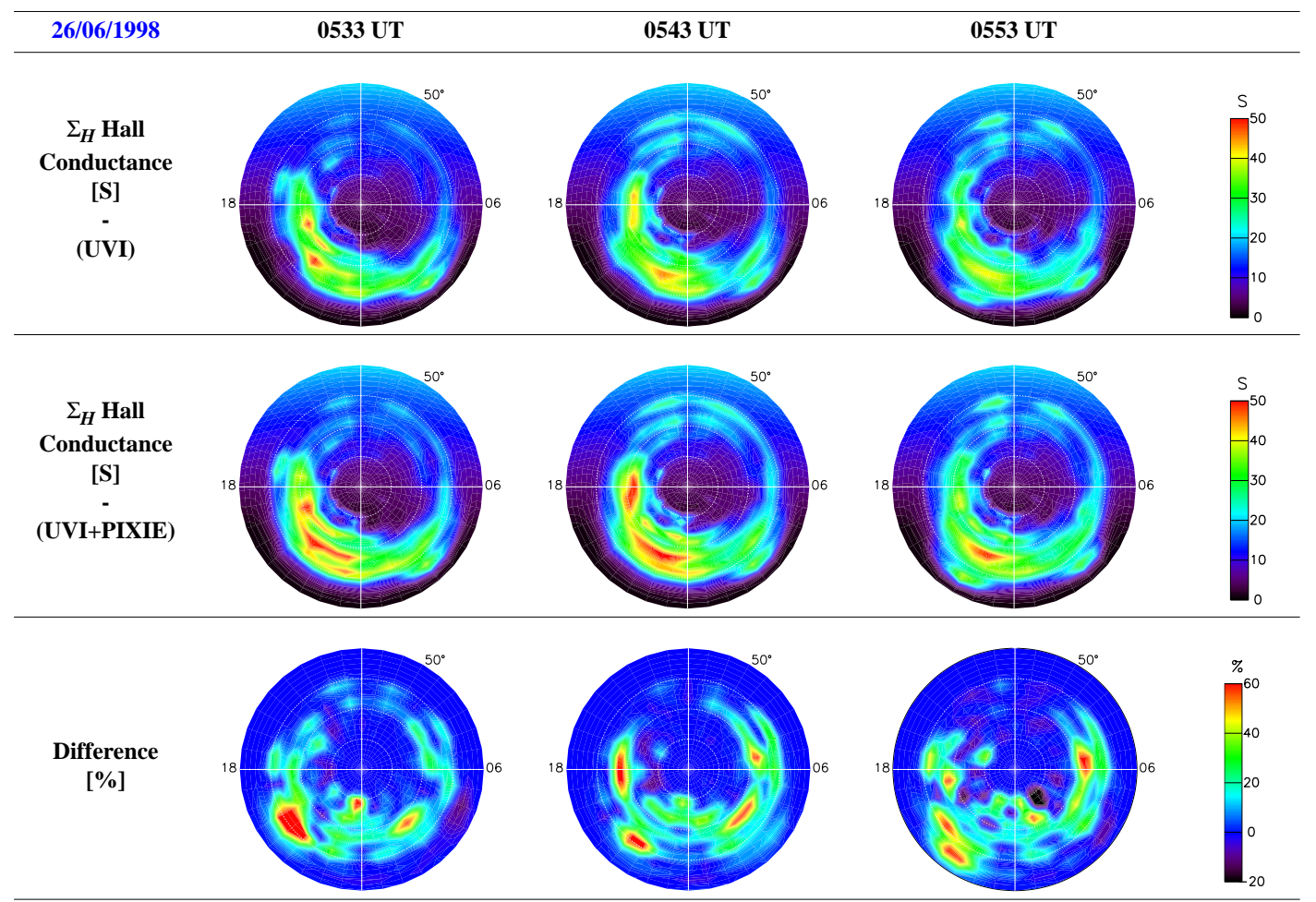

Fig. 2. Polar plots of the Hall conductance derived without (upper row) and with (middle row) PIXIE data between 05:30 and 06:00 UT on 26 June 1998. The differences in percent when including the PIXIE data are presented in the bottom row.

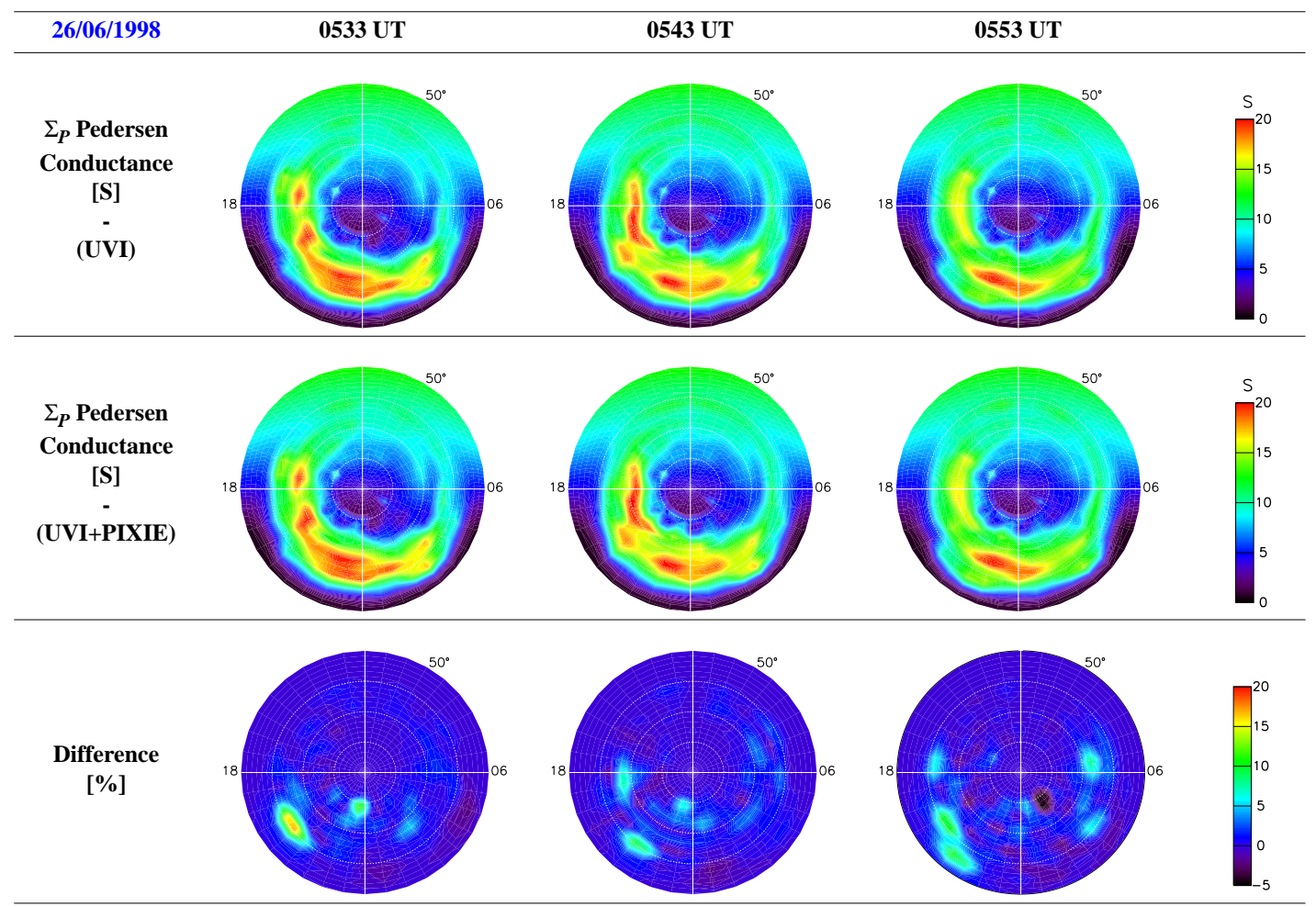

Fig. 3. Polar plots of the Pedersen conductance derived without (upper row) and with (middle row) PIXIE data between 05:30 and 06:00 UT on 26 June 1998. The differences in percent when including the PIXIE data are presented in the bottom row. 


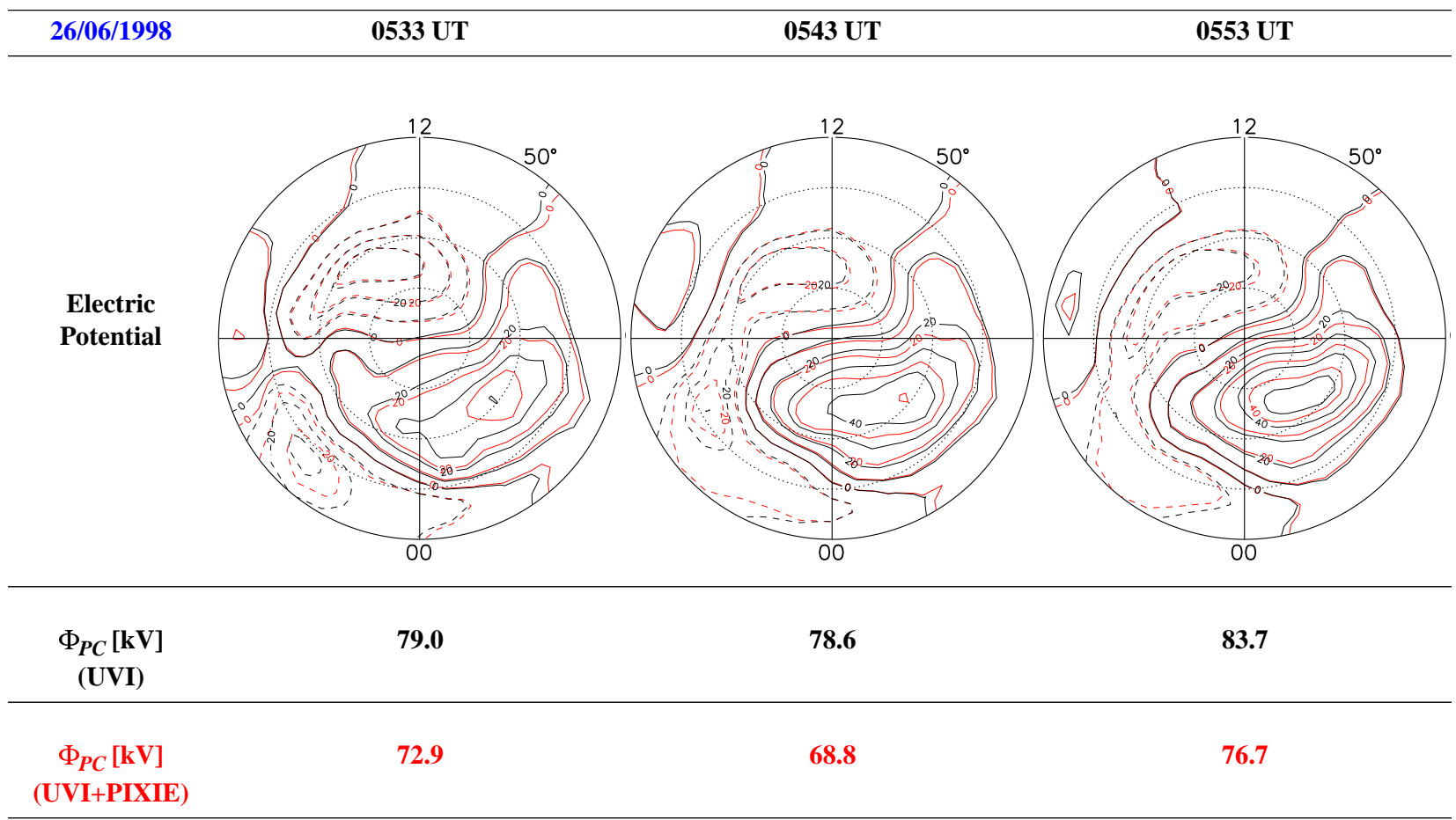

Fig. 4. Polar plots of the electric potential derived without (black contour lines) and with (red contour lines) PIXIE data between 05:30 and 06:00 UT on 26 June 1998.

including the PIXIE data. However, from the pre-midnight sector until the morning region, we find significant modifications of the electric field strength due to the precipitation of energetic electrons. Below each of the images presented in Fig. 4, we have listed the values of the calculated polar cap potential drop $\Phi_{P C}$, showing a clear reduction when including the PIXIE measurements.

Values of the potential drop during the whole time period when we have measurements from PIXIE and UVI between 03:00 and 08:00 UT on 26 June 1998, are presented in the upper row of Fig. 5a. The dashed line represents the potential drop derived without the PIXIE data, while the solid line gives the values after including the PIXIE measurements. The diamonds give the middle time in each integration period. We see that the inclusion of energetic electrons causes a reduction in the potential drop. The plot below presents the difference in percent with and without the PIXIE data, showing a general decrease between 5 and $10 \%$. In Fig. 5b, we give the values of the Joule heating rate $Q_{J}$ integrated over the Northern Hemisphere. Similarly to the electric potential, we find that the estimated Joule heating decreases when including the PIXIE measurements. For most of the time period investigated, the decrease is between 10 and $15 \%$, as shown in the bottom row of Fig. 5b. The larger decrease in Joule heating compared to that in the potential drop is not surprising, as Joule heating $Q_{J}$ depends on the square of the electric field $E$ according to the formula:

$Q_{J}=\Sigma_{P} E^{2}$
The inferred energy flux $Q_{A}$ by precipitating particles increases when we include the energetic electrons from PIXIE. At most, the increase is about $7 \%$ during the time period investigated from the event of 26 June 1998. Since Joule heating decreases when including the PIXIE data, we find that the energy flux $Q_{A}$ compared with Joule heating $Q_{J}$ becomes significantly more important. In Fig. 5c, we have plotted the ratio $Q_{J} / Q_{A}$. The dashed line representing the ratios without using the PIXIE data shows the highest ratios. When including the PIXIE data, the ratio decreases, as shown by the solid line. The difference sometimes exceeds $20 \%$. We note that the ratio is larger than 1 throughout almost the entire period, meaning that the energy due to Joule heating generally exceeds the energy flux deposited by precipitating particles. However, the difference between Joule heating and energy flux reduces significantly when including the PIXIE data.

From Fig. 5, we can conclude that the maximum change in the hemispheric integrated Joule heating rate from adding PIXIE observations is $\sim 17 \%$. However, there can be much larger decreases in localized regions, as shown in Fig. 6. Here we present global maps of Joule heating, showing local decreases sometimes exceeding $50 \%$ when including the PIXIE data. The changes in Joule heating take place in regions where there is a significant flux of energetic electrons. For instance, looking at the images from 05:33 UT, the upper row shows the strongest Joule heating stretching from about 13:00 until 02:00 MLT. Including the PIXIE data results in significant decreases of approximately 25 and 50\% in the pre-midnight sector after 19:00 MLT. This corresponds 


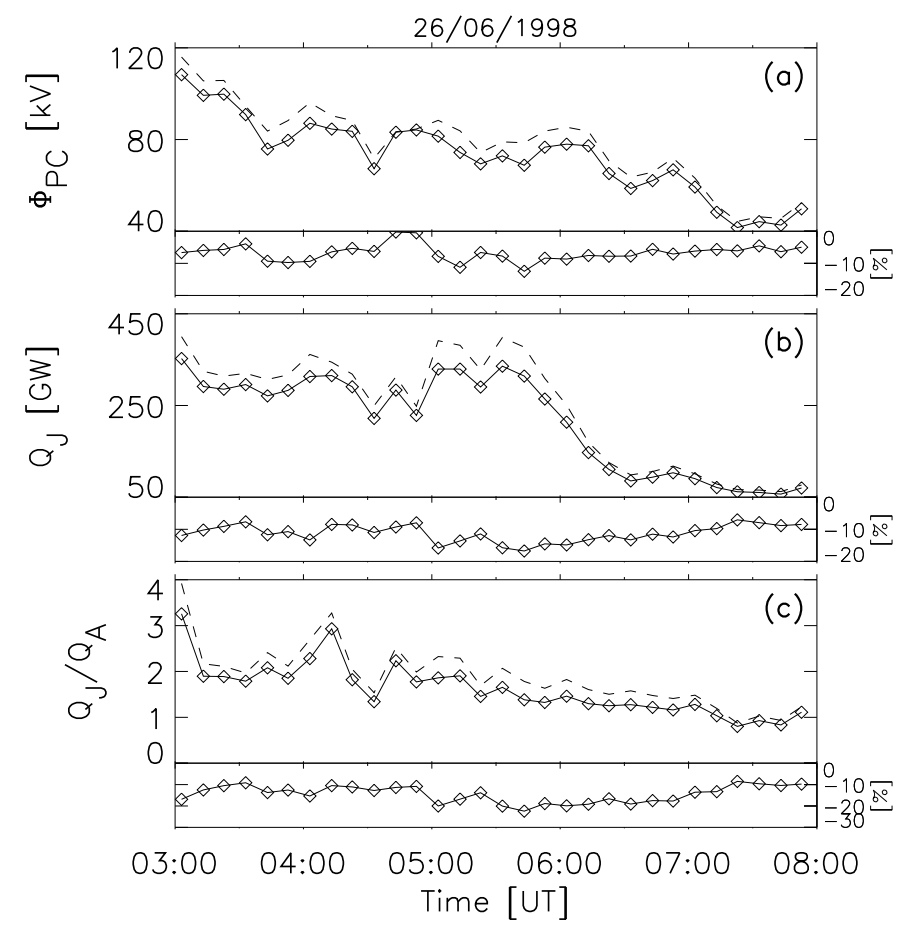

Fig. 5. (a) Polar cap potential drop $\Phi_{P C}$, (b) Joule heating rate $Q_{J}$ and (c) the ratio $Q_{J} / Q_{A}$ between Joule heating and energy flux estimated throughout the time interval between 03:00 and 08:00 UT on 26 June 1998. The parameters have been calculated without (dashed line) and with (solid line) PIXIE data. The differences in percent when including PIXIE measurements are also presented. well with the images of the Hall conductance in Fig. 2 from the same time period, showing the largest differences to take place in this pre-midnight sector.

During the whole time period between 03:00 and 08:00 UT on 26 June 1998, when we have PIXIE and UVI measurements, AMIE provides 9058 data values from regions covered by both instruments. These values are presented as a scatter plot in Fig. 7, showing the effects of energetic electrons occurring at different levels of conductances and Joule heating. The distribution of Hall conductance is given in Fig. $7 \mathrm{a}$ in terms of dots, giving the UVI derived values along the horizontal axis and the values when including the PIXIE measurements along the vertical axis. From Fig. 7a, we observe a rather systematic increase in the Hall conductance caused by the inclusion of energetic electrons. By performing a simple linear regression analysis, we find that the Hall conductance, on average, increases by $10 \%$ when taking into account the PIXIE measurements. This increase in the Hall conductance is indicated with the solid line representing a function $f(x)$ having a proportionality factor of 1.098. We also note that in some cases the values differ strongly, exceeding more than $100 \%$ when including the PIXIE data in the estimation of the Hall conductance. The dashed line having a proportionality factor of 1.0 is drawn to indicate the locations of the Hall conductance values in cases where the two data sets provide the same output. As inclusion of PIXIE data usually leads to a larger Hall conductance, we therefore find $84 \%$ of the dots located above the dashed line. In some cases the improved spectral characterization at higher energies by using PIXIE data results in a lower electron flux than calculated using extrapolated UVI spectra. This explains the dots located below the dashed line in Fig. 7a. We should point out that the individual dots represent a significant uncertainty considering the complex procedure to estimate electron energy spectra from combined PIXIE and UVI measurements, as described in Sect. 2. The uncertainties will show up as noise though, and not as a systematic error in our data. Taking the standard deviation on the slope of the regression line of 0.003 into account, we can therefore conclude that a larger estimated Hall conductance is to be expected when including PIXIE data in the calculations. A similar scatter plot is presented in Fig. 7b, giving the Pedersen conductance derived with and without the PIXIE data. Here we observe that almost all the values are located at the dashed line. A proportionality factor of 1.007 means that the Pedersen conductance remains very much unaffected by the increased electron flux at larger energies, in accordance with the results presented in Fig. 3. Effects of energetic electrons occurring at different Joule heating levels are presented in Fig. 7c, showing a significant reduction when taking the PIXIE data into account. By performing the linear regression analysis, we find that the Joule heating, on average, decreases by $15 \%$. Though the values vary significantly, with the largest local decrease exceeding $58 \%$.

In Fig. 8, we present the geomagnetic indices $A E(67)$, $A L(67)$ and $D_{s t}(17)$ from 31 July 1997 . The measurements from PIXIE and UVI covering the time period between 02:00 and 04:20 UT involve a clear and isolated substorm event. An abrupt intensification was seen in the $A E$ and $A L$ indices around 02:45 UT, with peak values exceeding 1300 and $-800 \mathrm{nT}$, respectively. In Fig. 9 we present three successive images of the distribution of Hall conductance from the later phases of the substorm, when the conductance maximum takes place on the morning side. We find that the high 


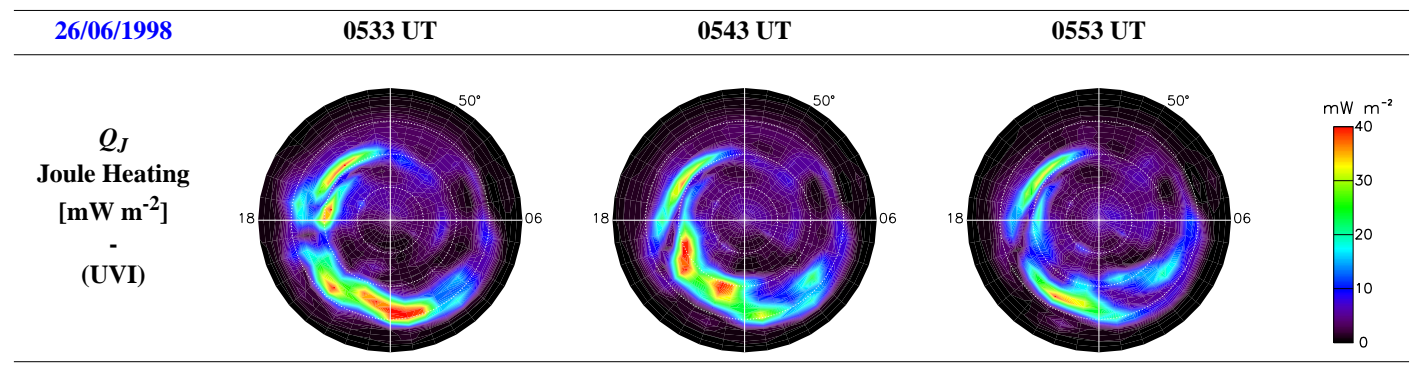
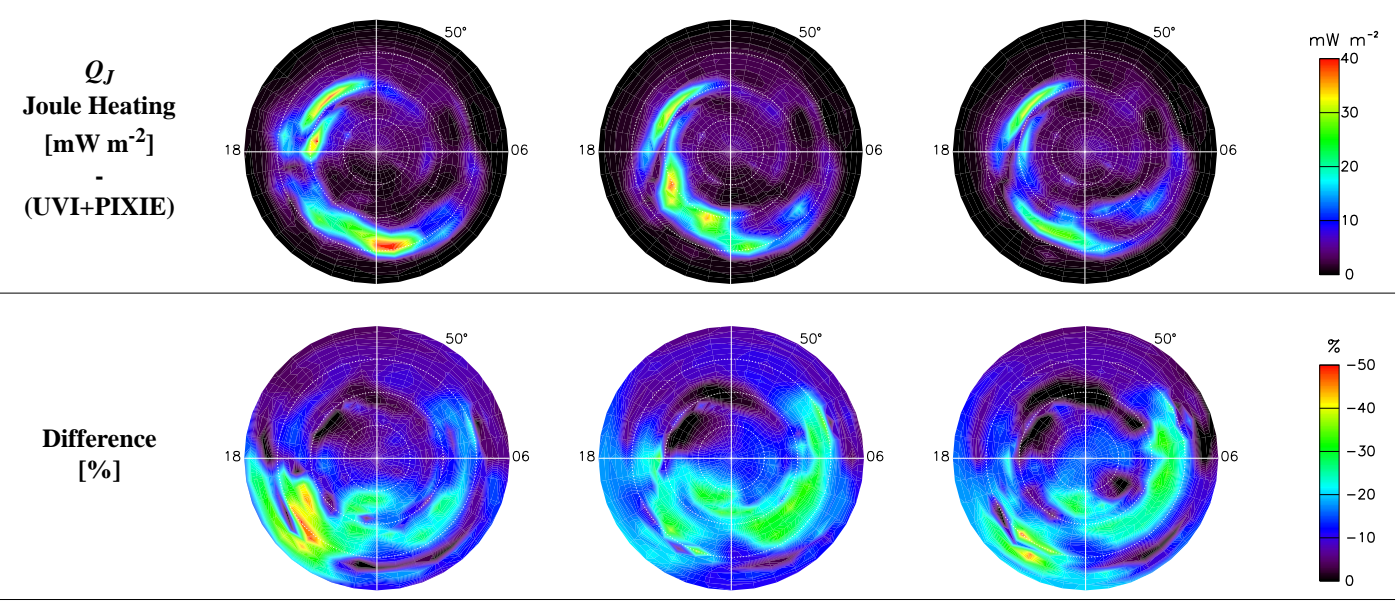

Fig. 6. Polar plots of Joule heating derived without (upper row) and with (middle row) PIXIE data between 05:30 and 06:00 UT on 26 June, 1998. The differences in percent when including the PIXIE data are presented in the bottom row.

energy electrons derived from the PIXIE data strongly increase the Hall conductance, in accordance with the results from the event on 26 June 1998.

Similarly, we find that the estimated Joule heating decreases, as presented in Fig. 10. In the upper row, where the PIXIE data have not been included, the images show maxima in both the postnoon sector as well as the morning sector. After including the energetic electrons from PIXIE, the images in the middle row reveal that the Joule heating maximum in the morning sector decreases significantly. However, the maximum in the afternoon sector remains fairly unaffected, as the precipitation of energetic electrons is negligible in these regions, according to Fig. 9.

Figure 11 shows the same trends as Fig. 5. Both the calculated potential drop and Joule heating are reduced when we take into account the energetic electrons. During the most active period after 02:45 UT, the potential drop decreases by as much as $13 \%$, while the Joule heating at two occasions decreases more than $20 \%$. The inferred energy flux increases in general around 5\% when including the PIXIE data, resulting in a decrease in the ratio between Joule heating and energy flux by 20 to $30 \%$.

\subsection{July 1997}

A scatter plot of the Hall conductance values given in Fig. 12a shows the distribution of the 1964 data values AMIE provides between 02:00 and 04:20 UT on 31 July 1997.
The linear regression analysis reveals that the Hall conductance, on average, increases by $13 \%$ and with a maximum local increase of $99 \%$ when including the PIXIE measurements. The Pedersen conductance in Fig. 12b remains more or less unaffected by the energetic electrons, in accordance with the results presented in Fig. 3 and Fig. 7b. A reduction by $19 \%$ and a maximum local decrease of about $39 \%$ is found in Fig. 12c when studying the PIXIE effects on the Joule heating values.

\subsection{August 1997}

The geomagnetic indices $A E(68), A L(68)$ and $D_{s t}(16)$ from 28 August 1997 are presented in Fig. 13. During the time interval between 03:00 and 10:00 UT when measurements from PIXIE and UVI were available, two relatively clear peaks can be seen in the $A E(68)$ and $A L(68)$ indices. The first intensification is rather extended in time from about 03:30 until 06:00 UT, with $A E$ exceeding $900 \mathrm{nT}$ and $A L$ reaching $-700 \mathrm{nT}$. This substorm took place during the main phase of a minor geomagnetic storm, as the $D_{s t}(16)$ decreased from around $-5 \mathrm{nT}$ at 03:00 UT to around $-48 \mathrm{nT}$ at 05:30 UT. Then the recovery phase commenced, as the $D_{s t}(16)$ index started to increase. However, around 07:00 UT, another intensification was observed as the magnitude of the $A E(68)$ and $A L(68)$ indices increased significantly, reaching almost 1100 and $-800 \mathrm{nT}$, respectively, around 07:55 UT. Thereafter, the activity slowly diminished. 


\section{6/06/1998}
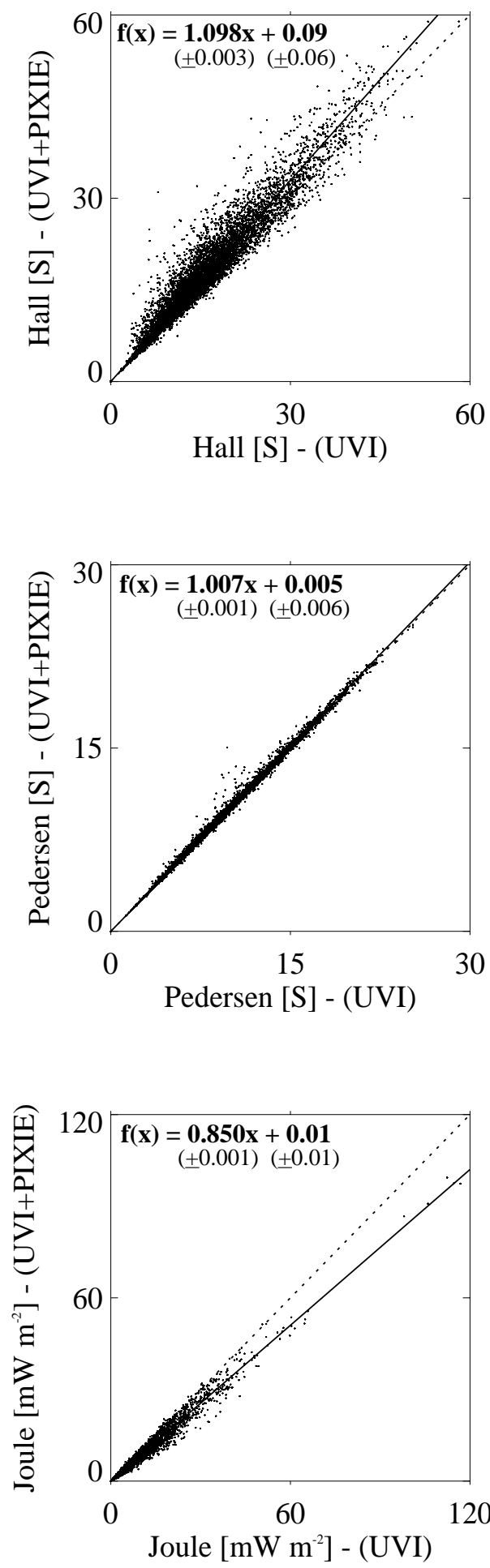

Fig. 7. (a) Hall conductances $\Sigma_{H}$, (b) Pedersen conductances $\Sigma_{P}$ and (c) Joule heating values $Q_{J}$ derived with and without the PIXIE data throughout the time interval between 03:00 and 08:00 UT on 26 June 1998. The data values are taken from the regions covered by the PIXIE and UVI instruments. The solid line results from a linear regression analysis of the data points.
In Fig. 14 we present similar plots, as presented in Fig. 5 and Fig. 11. Again we note the effects of the energetic electrons on polar cap potential, Joule heating and energy flux. Overall, the effects are less than the ones found during the event on 26 June 1998, and 31 July 1997. According to Fig. 14a, the calculated potential drop is generally reduced by $5 \%$ at most for the first geomagnetic disturbed period between 03:00 and 06:00 UT. The inferred Joule heating decreases by 5 to $10 \%$ during the same period, as shown in Fig. 14b. However, the second intensification after 07:00 UT seen in Fig. 13 results in relatively large effects. Figure $14 \mathrm{c}$ reveals that the ratio between Joule heating and energy flux is reduced by about $25 \%$ around 08:30 UT. Similar to Fig. 7 and Fig. 12, we also present in Fig. 15 the distribution of conductances and Joule heating values for the 5767 data values provided by AMIE between 03:00 and 10:00 UT on 28 August 1997.

By performing the linear regression analysis, we derive an average increase of the Hall conductance of $7.4 \%$, as given in Fig. 15a. This result is somewhat lower than the corresponding values of 10 and 13\% from the events of 26 June 1998, and 31 July 1997, respectively. Figure 15 further shows that the decrease in the Joule heating values caused by the energetic electrons, on average, reaches $15 \%$, while the Pedersen conductance remains practically unaffected by the PIXIE data.

\section{Discussion}

We have studied the effects of energetic electrons on ionospheric electrodynamics during periods of substorm activity occurring on 31 July and 28 August 1997, and 26 June 1998.

On 31 July 1997, we have measurements prior to and during an isolated substorm event. Before substorm onset around 02:40 UT, the PIXIE effects are minor, as shown in Fig. 11. This indicates that the growth phase was dominated by less energetic particles, in accordance with the statistical study by Østgaard et al. (1999) presented in Sect. 1. Figure 11 further shows that the effects of energetic electrons increase as the expansion phase commences. Østgaard et al. (2001) and Aksnes et al. (2002) have investigated this substorm event thoroughly, showing an eastward drift of the energetic electrons and the development of a maximum in the morning sector during the recovery phase of the substorm. This explains the significant effects of energetic electrons reducing the estimated Joule heating integrated over the Northern Hemisphere by more than $20 \%$ and the ratio between Joule heating and energy flux by almost $30 \%$. On 26 June 1998, the effects of energetic electrons are largest during the substorm event between 05:00 and 06:00 UT, according to Fig. 5. From Fig. 2, we now observe a shift westward of the Hall conductance maximum. At 05:33 UT, the maximum is located around 19:00 MLT. Ten minutes later, we find the largest Hall conductance in the MLT sector 17-18. This shift westward may be associated with a westward travelling surge (WTS). Ground magnetometer data from the station Barrow 


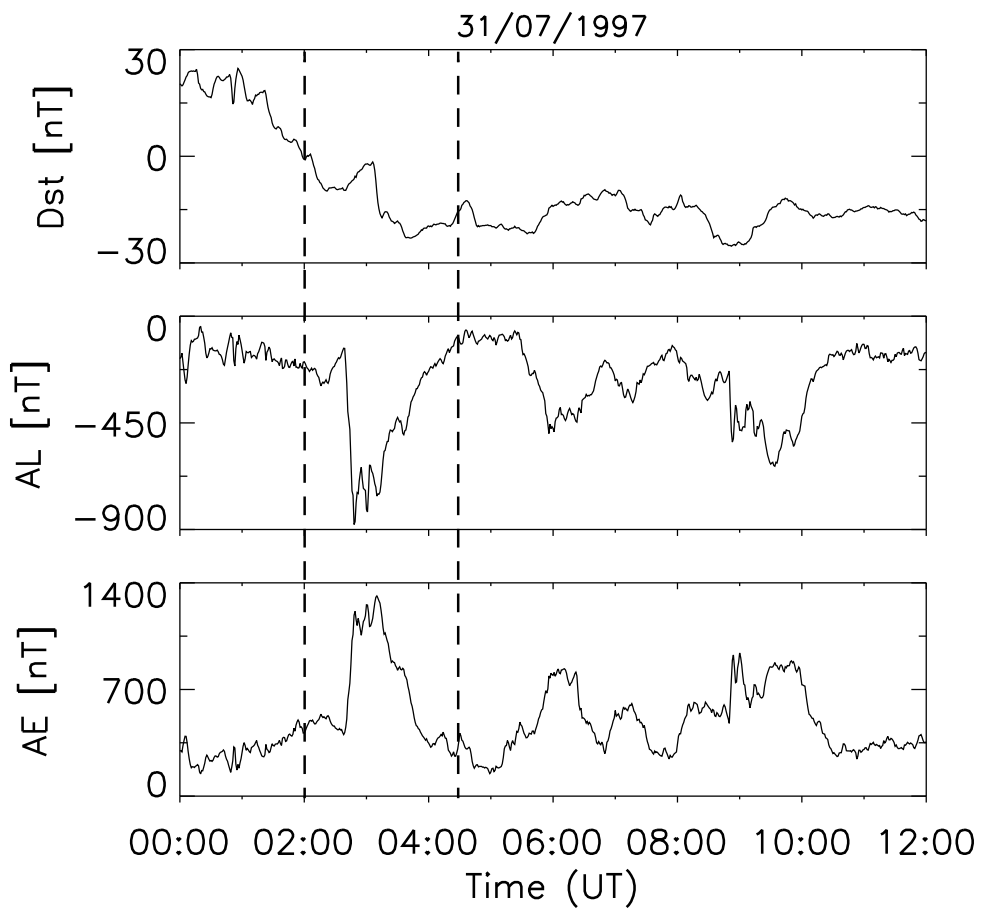

Fig. 8. The $A E, A L$ and $D_{s t}$-indices between 00:00 and 12:00 UT on 31 July 1997. $A E$ and $A L$ are calculated from 67 stations between 55 and $76^{\circ}$ in magnetic latitudes. $D_{s t}$ is calculated from 17 stations below $40^{\circ}$ in magnetic latitudes. The two vertical dashed lines indicate our time interval with data between 02:00 and 04:20 UT.

indicate the appearance of a WTS, as we observe typical features like a negative dip in the $\mathrm{H}$ component and a positive bay in the Y component. As summarized by Miller and Vondrak (1985), WTS is associated with energetic electrons.

In Fig. 14, we show effects of energetic electrons on ionospheric electrodynamics during the event of 28 August 1997. The second intensification starting around 07:00 UT results in large differences, in accordance with the results from 31 July 1997, and 26 June 1998. However, we also note that the first intensification this day between 03:00 and 06:00 UT only leads to minor differences. Except for the results around 04:30 UT, the effects of energetic electrons are less than we might have expected when observing the relatively large increase in the geomagnetic indices. This results from the fact that the precipitating electrons were mostly less energetic during this time period. We note that the $A E$ and $A L$ indices peaked at about $900 \mathrm{nT}$ and $-700 \mathrm{nT}$, respectively. During the second intensification on 28 August, the $A E$ index reached almost $1100 \mathrm{nT}$ and the $A L$ index was close to $-800 \mathrm{nT}$. The two other events from 31 July and 26 June both show much larger values of the $A E$ and $A L$ indices, as presented in Fig. 1 and Fig. 8.

In Fig. 16a we give an example of a typical precipitating electron energy spectrum derived from PIXIE and UVI measurements. The solid line represents the full spectral characterization where both PIXIE and UVI data are taken into account. While the lower electron energies are determined from UVI data, the PIXIE measurements enable us to characterize the most energetic electrons. Also plotted is a dashed line showing the situation without PIXIE data, where the UVI derived electron spectrum has been extrapolated towards higher energies. Such an extrapolation is obviously not sufficient here, as we see a significant drop in the electron flux at higher energies. As pointed out in Sect. 1, the PIXIE data may sometimes reveal a lower electron flux at higher energies than provided by the extrapolated UVI spectra. This explains the cases with negative differences when including PIXIE data in Figs. 2, 3, 7, 9, 12, and 15. Nevertheless, from the same figures we can conclude that the situation presented in Fig. 16a, showing a higher electron flux when including PIXIE data, is by far the most typical. In Fig. 16b we present the effects on the electron energy deposition from the two situations described in Fig. 16a with and without PIXIE data. The dashed line giving the height profile of the electron energy deposition based on the extrapolated UVI derived spectrum falls off steeply below $100 \mathrm{~km}$. At altitudes lower than $90 \mathrm{~km}$, the electron energy deposition values are practically insignificant, as the values have dropped below $10 \mathrm{keV} \cdot \mathrm{cm}^{-3} \cdot \mathrm{s}^{-1}$. In comparison, the solid line representing the energy deposition from the electron spectrum derived using combined PIXIE and UVI measurements remains large in the upper part of the D-region and first starts to fall off drastically below $80 \mathrm{~km}$. We find that including PIXIE data increases the total height-integrated energy deposition by about $40 \%$. However, if we only consider the region below $100 \mathrm{~km}$, the increase is more than $600 \%$.

In Fig. 16c, we present similar height profiles of the Hall conductance. We note the discrepancy below $100 \mathrm{~km}$, resulting in a large difference in the total height-integrated Hall conductivity. Without PIXIE data, we derive a Hall conductance of $27 \mathrm{~S}$. By including the information from the Xray measurements, the resulting Hall conductance value is $39 \mathrm{~S}$, an increase of $\sim 44 \%$. The importance of the energetic electrons for the Hall conductance has been pointed out by 


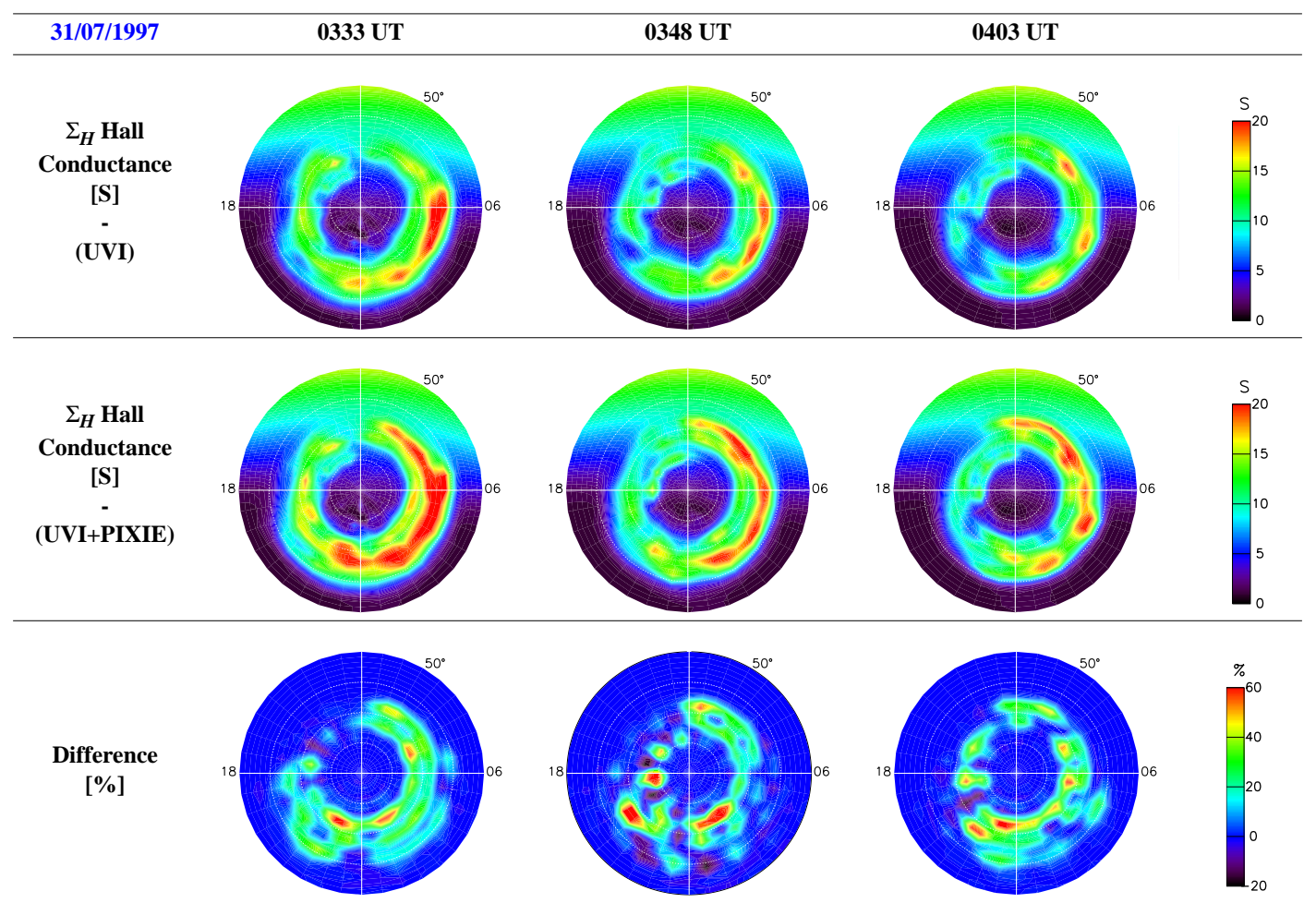

Fig. 9. Polar plots of the Hall conductance derived without (upper row) and with (middle row) PIXIE data between 03:30 and 04:05 UT on 31 July 1997. The differences in percent when including the PIXIE data are presented in the bottom row.

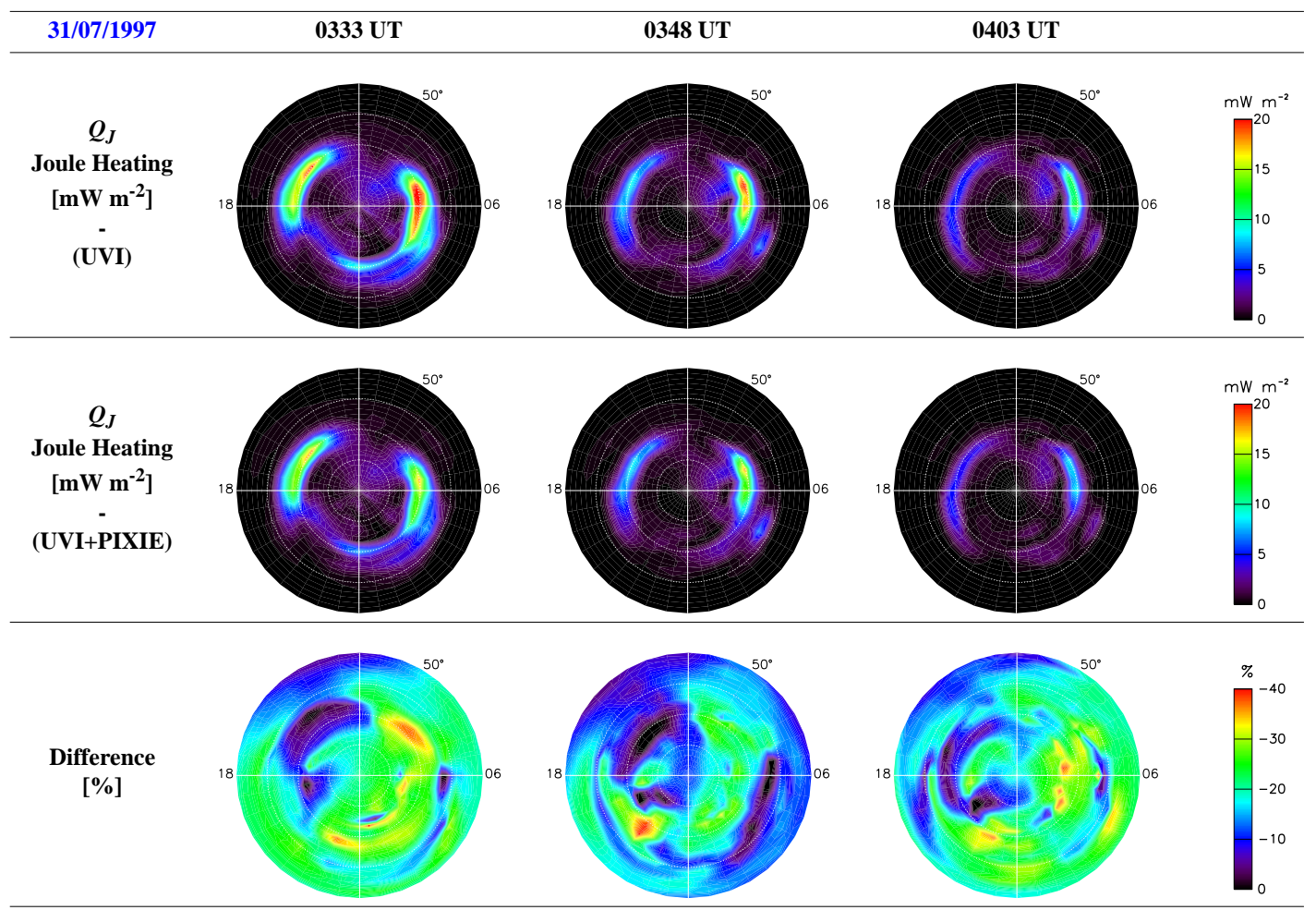

Fig. 10. Polar plots of Joule heating derived without (upper row) and with (middle row) PIXIE data between 03:30 and 04:05 UT on 31 July 1997. The differences in percent when including the PIXIE data are presented in the bottom row. 


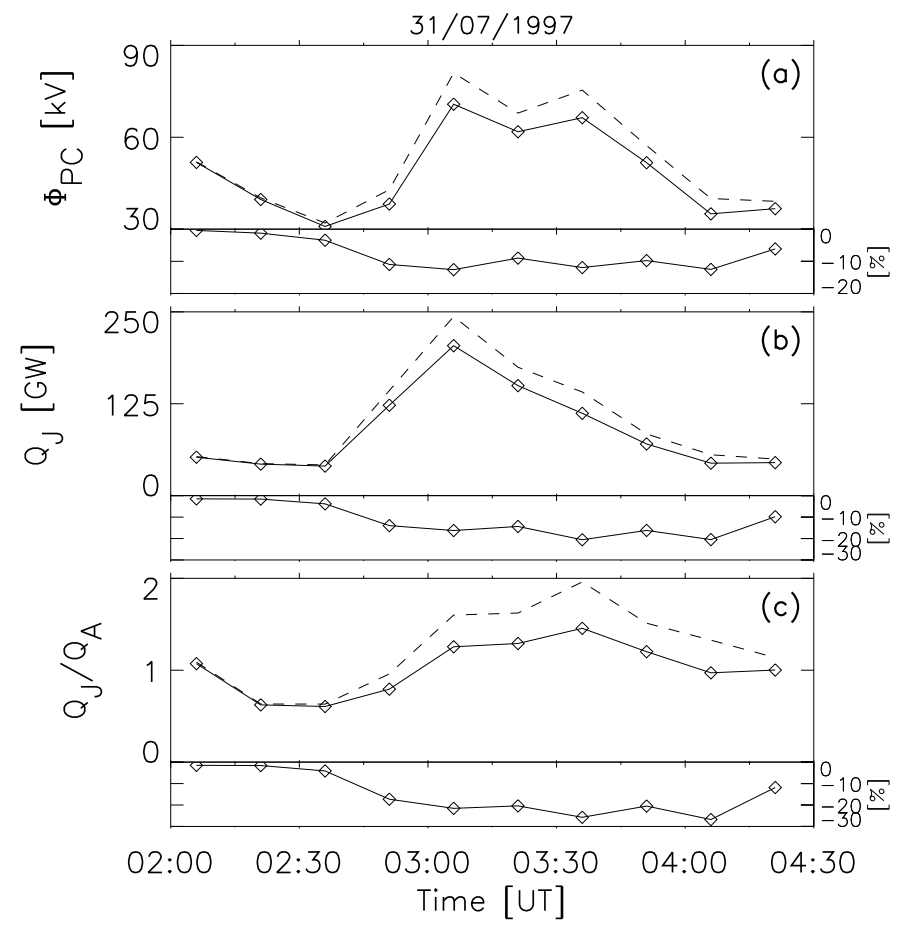

Fig. 11. (a) Polar cap potential drop $\Phi_{P C}$, (b) Joule heating rate $Q_{J}$ and (c) the ratio $Q_{J} / Q_{A}$ between Joule heating and energy flux estimated throughout the time interval between 02:00 and 04:20 UT on 31 July 1997. The parameters have been calculated without (dashed line) and with (solid line) PIXIE data. The differences in percent when including PIXIE measurements are also presented.

Schlegel (1988). From two years of EISCAT data, 8337 conductivity profiles were calculated within a height region between 90 and $180 \mathrm{~km}$. The maximum Hall conductivity was usually located at $109 \mathrm{~km}$. In comparison, the largest Hall conductivity in Fig. 16c is at an altitude of $108 \mathrm{~km}$, along with a significant contribution to the Hall conductance at lower heights. During times with very energetic particle precipitation, Schlegel sometimes found the maximum in Hall conductance at heights below $100 \mathrm{~km}$. For such events, the conductivity profiles were extrapolated exponentially down to $75 \mathrm{~km}$ altitude, in order to derive a more accurate heightintegrated Hall conductivity.

From Fig. 16, we can conclude that the difference between including PIXIE data or not may be tremendous in the lower E-region below $100 \mathrm{~km}$. Significant effects on physical processes in the lower thermosphere and mesosphere should be expected. When interpreting the results found in this study, though, we need to keep in mind the limitations described in Sect. 2.5. First of all, the rather coarse PIXIE resolution $(600-900 \mathrm{~km})$ prevents us from identifying localized structures in the electron precipitation. Secondly, the procedure for establishing electron spectra and thereafter calculating ionospheric conductances from PIXIE and UVI measurements may also be a source of uncertainty. As explained in Sect. 2.4., several assumptions and relations have been incorporated in the computer code used to infer height profiles of the ionization. We should therefore be careful when discussing ionospheric effects at specific altitudes from the investigation performed. Nevertheless, the results presented in Sect. 4. undoubtedly indicate that the inclusion of PIXIE data may have a large effect on the ionospheric electrodynamics.

\subsection{Effects on the electric field}

The large-scale ionospheric electric field has its origin in the interaction between the magnetosphere and the solar wind, and its configuration depends on the conditions of the interplanetary magnetic field (IMF). During periods of a southward pointing IMF, a two-cell electric convection pattern is established at higher latitudes. The electric potential drop across the polar cap is calculated as the difference between the minimum and maximum electric potentials and is often used to compare different electrodynamical states. Particle precipitation leads to an enhancement of ionospheric conductivities, resulting in electric polarization fields and thereby a modification of the electric field in the ionosphere locally (Bostrøm, 1973). Significant increases in the Hall conductance when including the PIXIE data during periods of substorm activity are seen in Figs. 2 and 9. The largest local effects of energetic electrons on the Hall conductances reach about $100 \%$, as shown in Fig. 7a, Figs. 12a and 15a. By assuming that the magnetosphere acts as a current generator, the computational effect of a larger Hall conductance from the AMIE calculations is a reduction of the estimated electric field. This has been shown in Figs. 4a, 11a and 14a. Such an anticorrelation between Hall conductance and ionospheric electric field has been reported in several papers using measurements from rockets (Wescott et al., 1969; Wentworth, 1970; Evans et al., 1977; Marklund et al., 1982), satellites (Shue and Weimer, 1994; Johnson et al., 1998), and radars (de la Beaujardière et al., 1977; Kirkwood et al., 1988; Opgenoorth et al., 1990; Aikio et al., 1993; Lanchester et al., 1996). 


\section{$31 / 07 / 1997$}
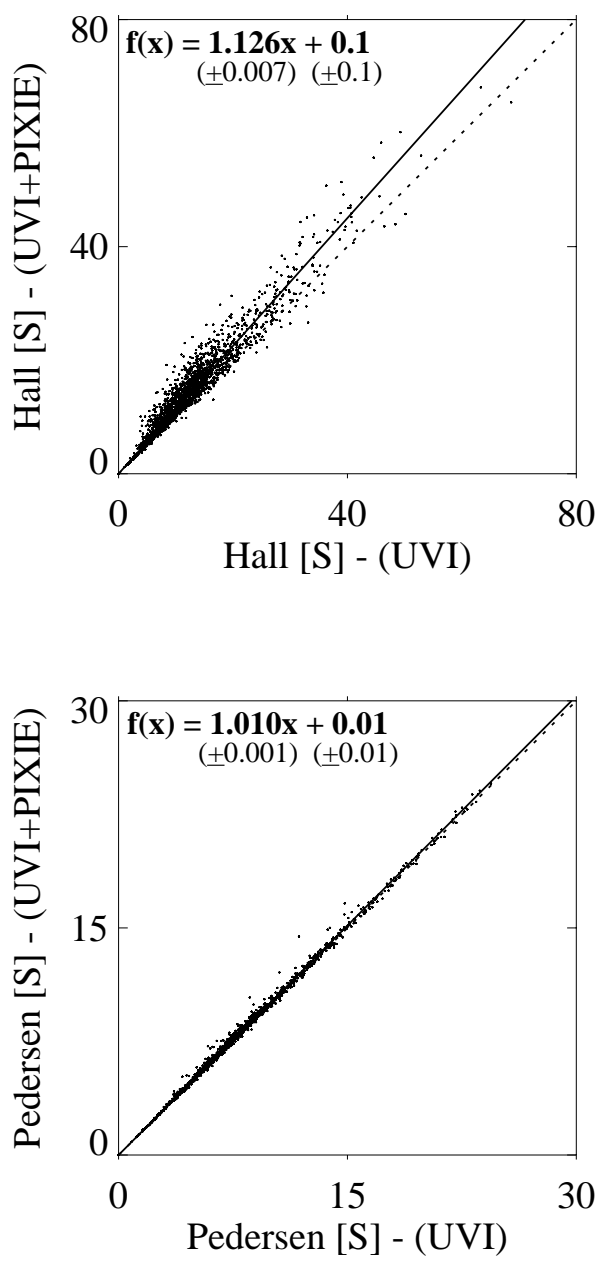

(b)

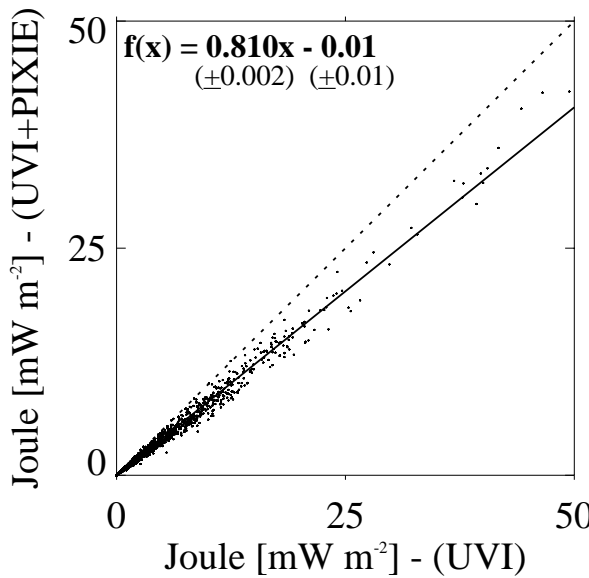

Fig. 12. (a) Hall conductances $\Sigma_{H}$, (b) Pedersen conductances $\Sigma_{P}$ and (c) Joule heating values $Q_{J}$ derived with and without the PIXIE data throughout the time interval between 02:00 and 04:20 UT on 31 July 1997. The data values are taken from the regions covered by the PIXIE and UVI instruments. The solid line results from a linear regression analysis of the data points.

\subsection{Effects of proton precipitation}

The UVI camera is potentially sensitive to protons, as mentioned in Sect. 2.2. According to Frey et al. (2001), LBH emissions may contain contributions from proton excitation, though, this should be limited to regions with strong proton precipitation. Particle observations from polar orbiting satellites (Hardy et al., 1989, 1991; Newell et al., 1991) and ground-based optical $\mathrm{H}$ emission observations (Creutzberg et al., 1988) show that the proton aurora can be of particular importance in the cusp and at the equatorward boundary of the auroral oval before midnight. Even though the statistical studies by Hardy et al. (1989) and Galand et al. (2001) show that electrons are the dominant source of ionization, protons, on average, contribute $\sim 15 \%$ to the total energy inferred. Protons precipitating in the atmosphere are treated as electrons in the UVI calculations, as the measured UV-emissions are assumed to be caused by precipitating electrons. This may lead to an underestimation of the electron density, according to a study by Galand et al. (1999). Galand et al. (1999) investigated the ionization by energetic protons in the auroral atmosphere using the Thermosphere-Ionosphere Electrodynamics General Circulation Model (Richmond et al., 1992). First, they calculated the ionospheric ionization caused by proton precipitation. Then they treated the protons as electrons, and showed that the resulting electron density was being underestimated. The largest difference occurred around $130 \mathrm{~km}$, near the region where the Pedersen conductivity peaks. This indicates that the Pedersen conductance may change somewhat when treating protons as electrons. A proton with an energy of $10 \mathrm{keV}$ will deposit most of its energy in this height region around $130 \mathrm{~km}$ (Rees, 1982). In comparison, an electron with a similar energy of $10 \mathrm{keV}$ can penetrate down below $110 \mathrm{~km}$ (Rees, 1963). For a proton to penetrate down to approximately $105 \mathrm{~km}$ where the Hall conductivity is largest, an energy of almost $100 \mathrm{keV}$ is needed (Rees, 1982). According to Hardy et al. (1989) the proton aurora can typically be expressed as a Maxwellian with a characteristic energy between 1 and $20 \mathrm{keV}$, indicating that the Hall conductance, in general, should be more or less unaffected by proton precipitation. If we assume that precipitating protons takes place during the three events of 31 July and 28 August 1997, and 26 June 1998, this might affect the calculation of Pedersen conductance. However, the possible change in the Pedersen conductance should be the same for a calculation with and without the PIXIE data, meaning that the proton aurora should not affect the results presented in this study. In order for proton precipitation to make a significant impact on the results, we need precipitating protons in the energy range of $100 \mathrm{keV}$ or more. Since the protons do not produce measurable X-rays because of their large mass compared with electrons, we might underestimate the Hall conductance during such a situation. Taking energetic protons in the energy range of $100 \mathrm{keV}$ into account, we should then find the effects presented in Sect. 4 to be slightly larger. 


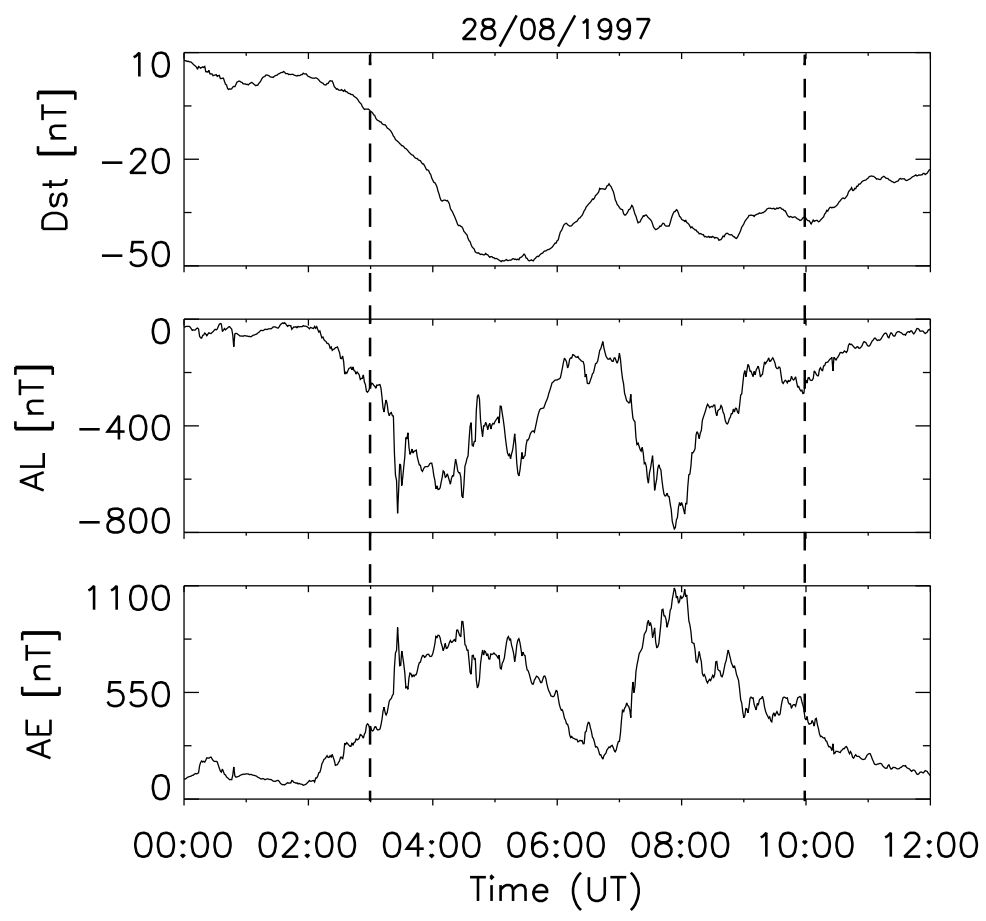

Fig. 13. The $A E, A L$ and $D_{s t}$-indices between 00:00 and 12:00 UT on $28 \mathrm{Au}-$ gust 1997. $A E$ and $A L$ are calculated from 68 stations between 55 and $76^{\circ}$ in magnetic latitudes. $D_{s t}$ is calculated from 16 stations below $40^{\circ}$ in magnetic latitudes. The two vertical dashed lines indicate our time interval with data between 03:00 and 10:00 UT.

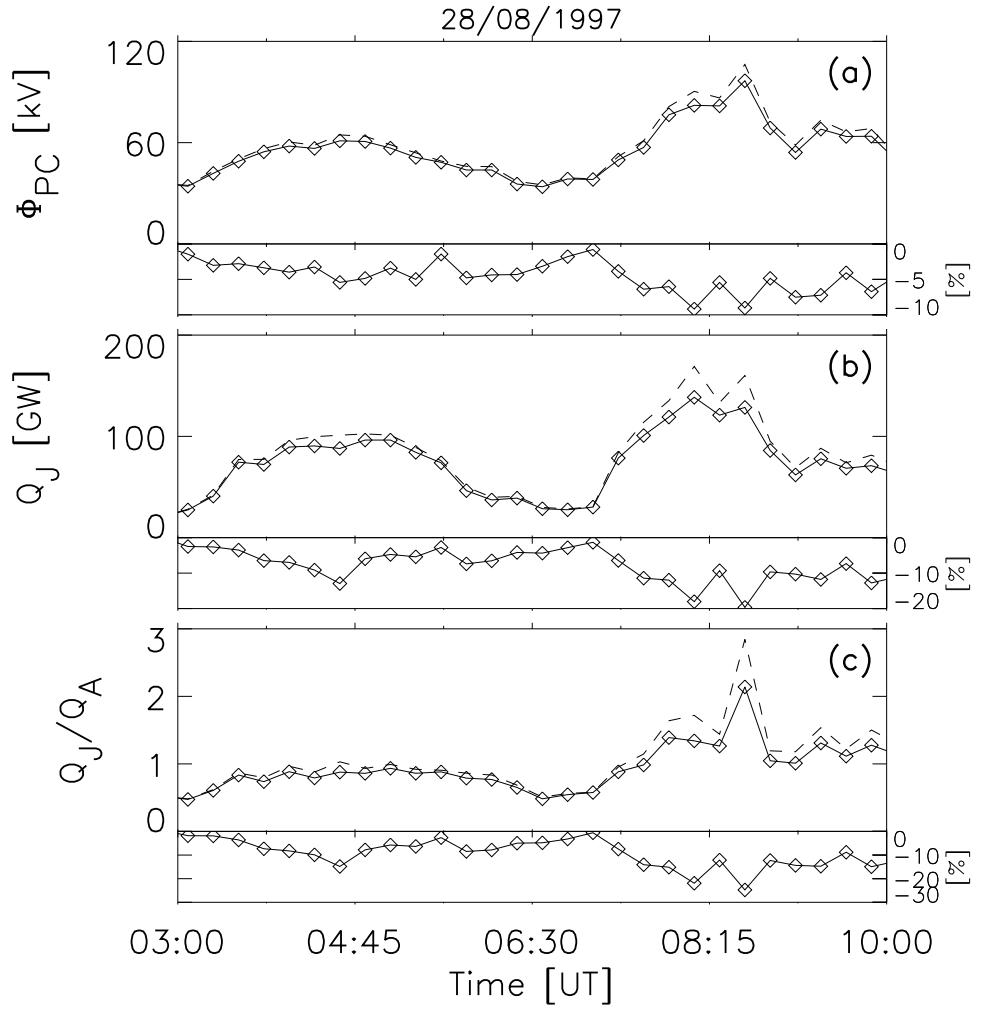

Fig. 14. (a) Polar cap potential drop $\Phi_{P C}$, (b) Joule heating rate $Q_{J}$ and (c) the ratio $Q_{J} / Q_{A}$ between Joule heating and energy flux estimated throughout the time interval between 03:00 and 10:00 UT on 28 August 1997. The parameters have been calculated without (dashed line) and with (solid line) PIXIE data. The differences in percent when including PIXIE measurements are also presented. 


\section{8/08/1997}
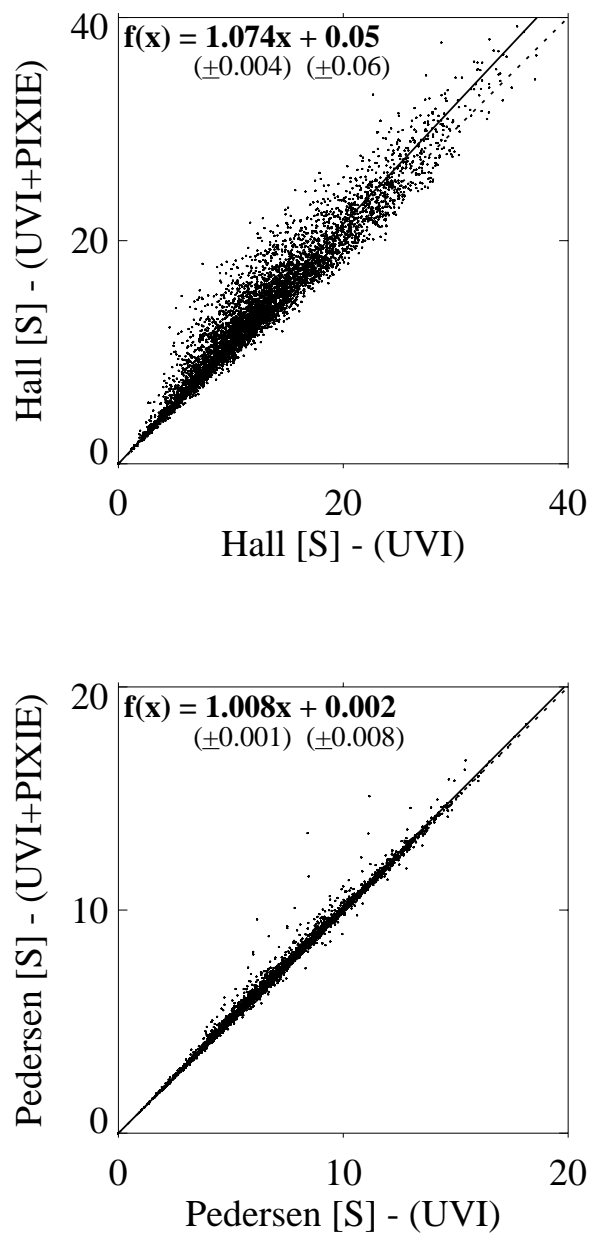

(b)

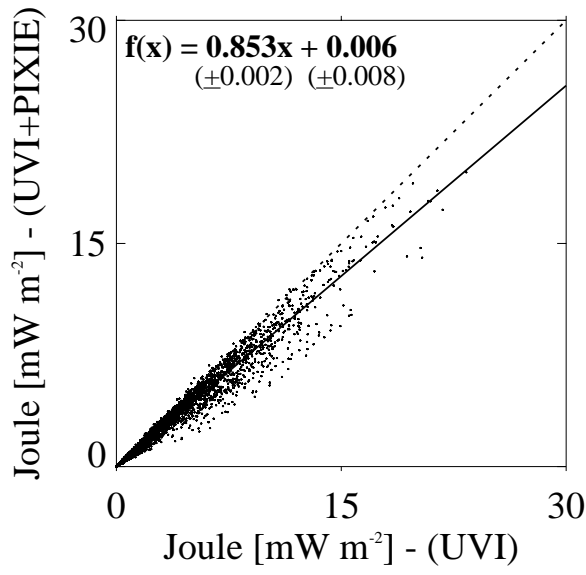

Fig. 15. (a) Hall conductances $\Sigma_{H}$, (b) Pedersen conductances $\Sigma_{P}$ and (c) Joule heating values $Q_{J}$ derived with and without the PIXIE data throughout the time interval between 03:00 and 10:00 UT on 28 August, 1997. The data values are taken from the regions covered by the PIXIE and UVI instruments. The solid line results from a linear regression analysis of the data points.

\subsection{Joule Heating vs. $A E$}

Several studies have investigated and found a nearly linear relationship between hemispheric integrated Joule heating and the $A E$ index. Such studies are motivated by the fact that we are often only able to provide Joule heating in localized regions. A possible relation with a geomagnetic index like $A E$ means we can estimate Joule heating continuously over the entire polar region. Papers report a proportionality factor between the Joule heating rate and the $A E$ index ranging from 0.16 to $0.54 \mathrm{GW} / \mathrm{nT}$ (Ahn et al., 1983b; Baumjohann and Kamide, 1984; Richmond et al., 1990; Cooper et al., 1995; Lu et al., 1996, 1998). The discrepancy between the studies may be attributed to the fact that different methods are used to obtain Joule heating and the $A E$ index. Both Ahn et al. (1983b) and Baumjohann and Kamide (1984) used the Kamide-Richmond-Matsushita algorithm (Kamide et al., 1981). However, while Ahn et al. (1983b) derived the conductances on the basis of ground magnetic perturbations, Baumjohann and Kamide made use of an improved version (Kamide et al., 1982) of the statistical conductance model developed by Spiro et al. (1982). Like the study presented in this paper, Richmond et al. (1990), Cooper et al. (1995) and Lu et al. $(1996,1998)$ applied the AMIE procedure. Though Richmond et al. adopted $A E(12)$ in their analysis, the other papers calculated $A E$ from the north-south component of the magnetic perturbations measured by all available magnetometer stations in the high-latitude auroral zone. Cooper et al. estimated a proportionality factor of $0.54 \mathrm{GW} / \mathrm{nT}$ when using $A E(12)$. However, when using a multistation-derived $A E$ from AMIE, they found the relation between Joule heating and the $A E$ index to be $0.28 \mathrm{GW} / \mathrm{nT}$.

We have done a similar investigation with the studies described here, by performing a linear regression analysis. When using the Joule heating derived without the PIXIE data, we find the proportionality factors to vary between 0.15 and 0.26 , meaning that we are in the lower end of the results found by others. Including the effects of energetic electrons results in even lower proportionality factors, as presented in Fig. 17.

For the events of 31 July and 28 August 1997, we find proportionality factors of 0.15 and $0.13 \mathrm{GW} / \mathrm{nT}$, respectively. On 26 June 1998, we obtain a somewhat larger value of $0.23 \mathrm{GW} / \mathrm{nT}$. While the isolated substorm event of 31 July takes place during a non-storm period and the event of 28 August occurs during a minor geomagnetic storm, the substorm activity investigated on 26 June is related to a severe storm with the $D_{s t}$ index reaching a minimum value of $-128 \mathrm{nT}$. The large proportionality factor established between the Joule heating and the $A E$ index for the event of 26 June may be attributed to the intense geomagnetic storm condition for this date. A characteristic of a geomagnetic storm is a strong convective electric field (Gonzalez et al., 1994), indicating that the electric field may contribute more to the ionospheric current responsible for the $A E$ values during storms than during non-storm conditions. As Joule heating depends strongly on the electric field strength, we should 

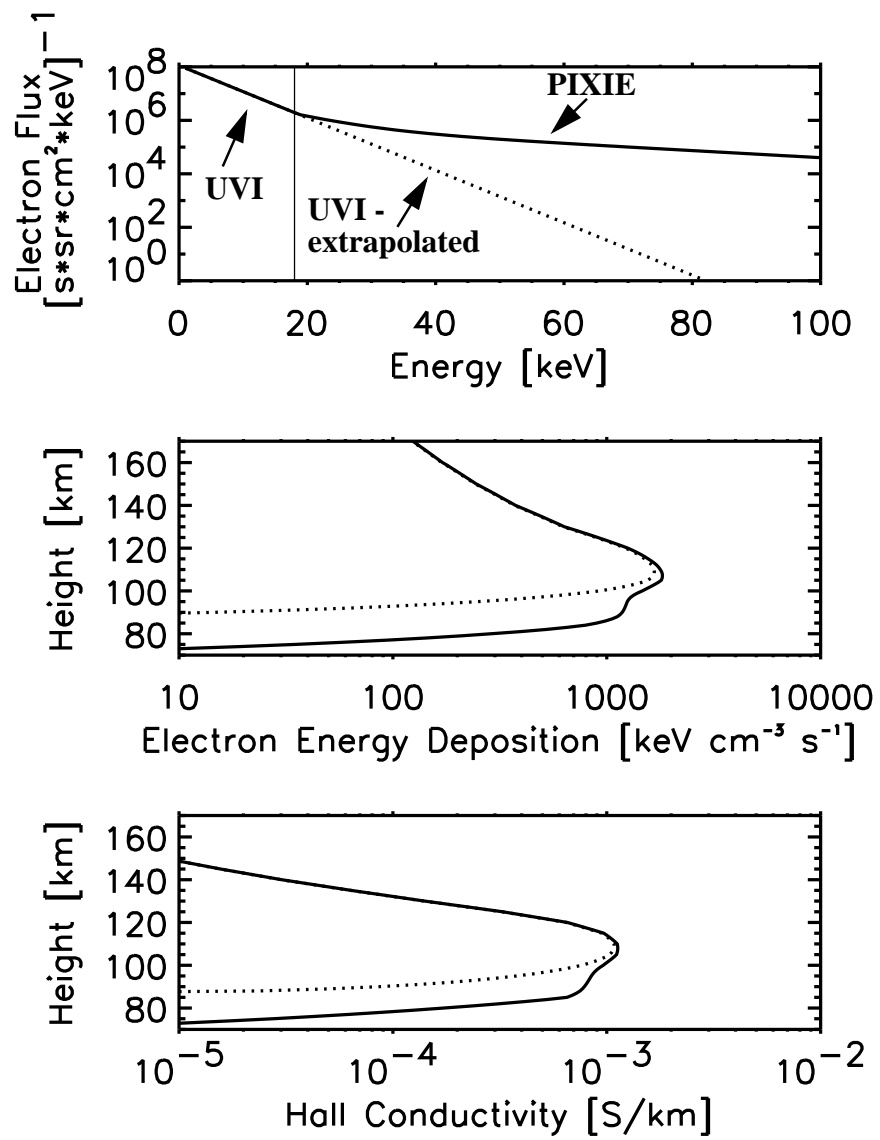

therefore expect a larger ratio between Joule heating and $A E$ index during storm periods. When looking at the different papers investigating this relationship using the AMIE procedure, we find such a tendency. Richmond et al. (1990) and Lu et al. (1996) study non-storm events and find proportionality factors ranging between 0.16 and $0.21 \mathrm{GW} / \mathrm{nT}$. Cooper et al. (1995) and Lu et al. (1998) find larger values between 0.25 and $0.54 \mathrm{GW} / \mathrm{nT}$ when studying storm events. A more thorough investigation is needed, though, for this suggested relationship between Joule heating, $A E$ index and geomagnetic storm condition.

From Fig. 17, we see that the linear correlation coefficient $r$ is high for all events, ranging from 0.88 to 0.94 . However, we should point out that the number of points is limited. For the events on 28 August 1997, and 26 June 1998, we have 34 and 30 data points, respectively. From the isolated substorm event on 31 July 1997, we have only 10 values. Therefore, one must be cautious when interpreting the results. Even though the statistics are rather limited, the results nevertheless show that the Joule heating turns out to be lower than previous studies have reported. The events of 31 July and 28 August, operating with proportionality factors of 0.15 and $0.13 \mathrm{GW} / \mathrm{nT}$, respectively, provide lower values for the relationship between Joule heating and $A E$ than found by others studying non-storm events. Likewise, the proportionality factor of $0.23 \mathrm{GW} / \mathrm{nT}$ for the event of 26 June is less than that found by previous studies using data from storm time conditions.

\subsection{Effects on energy budget}

We have found that the inferred Joule heating integrated over the Northern Hemisphere decreases by up to 20 percent when energetic electrons are taken into account. According to Fig. 5c, Fig. 11c and Fig. 14c, the ratio between Joule heating and electron energy flux decreases even more, as the calculated energy flux increases when we include the PIXIE data. These results show that auroral energy input by precipitating particles probably contributes relatively more to the total energy budget than previous papers have reported. One of the fundamental questions in space physics involves the energy coupling between the solar wind and the Earth's magnetosphere. The energy budget during magnetic storms and substorms has been evaluated and presented in several papers in the literature (Akasofu, 1981; Harel et al., 1981; Stern, 1984; Tsurutani and Gonzalez, 1995; Lu et al., 1995, 1998; Knipp et al., 1998; Østgaard et al., 2002a). The studies agree that the most important forms of energy dissipation in the near-Earth space are the magnetospheric ring current injection, atmospheric Joule heating and the energy flux carried by precipitating particles. However, the relative importance of the different energy forms is still much argued. Most studies 

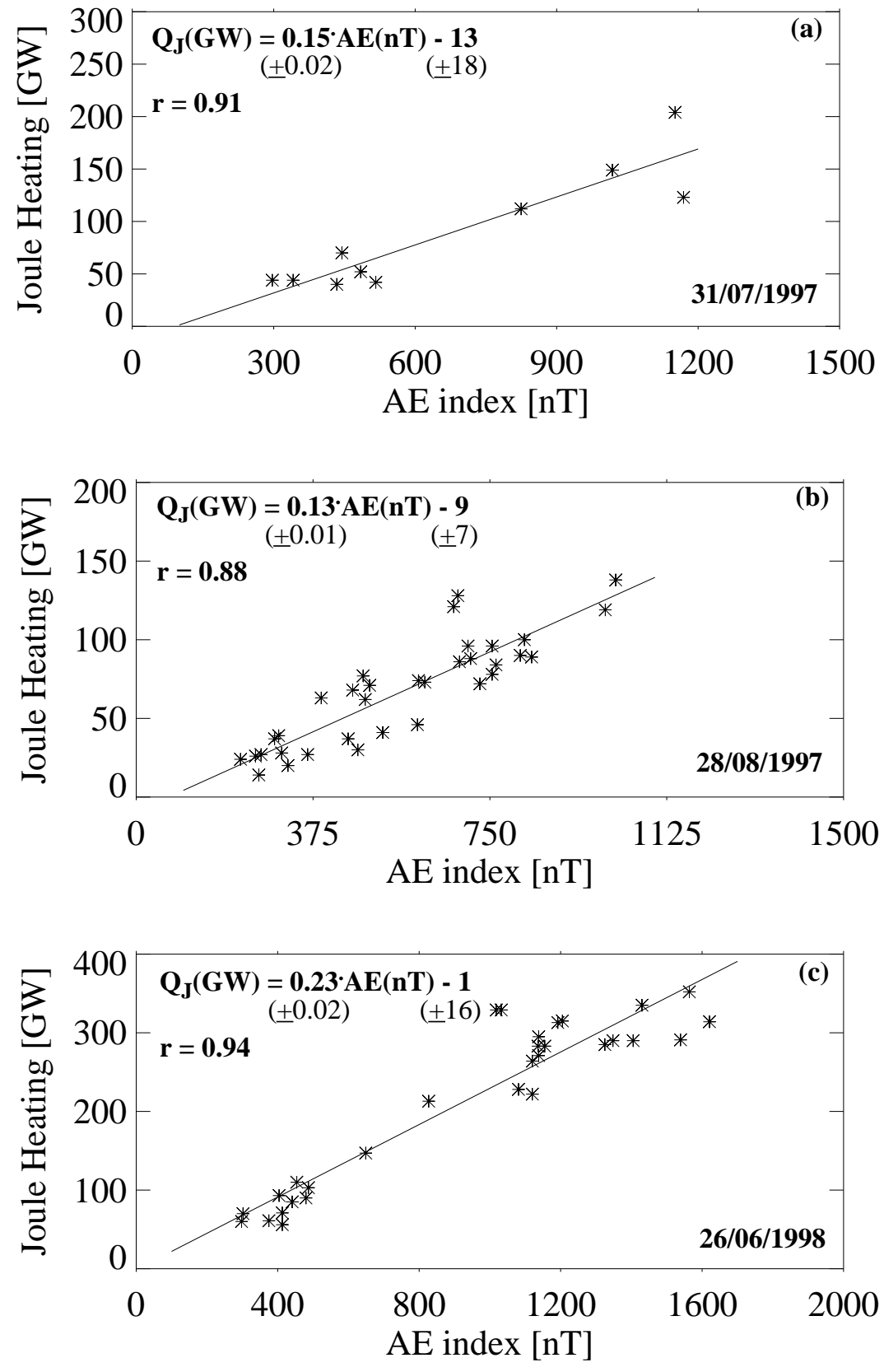

Fig. 17. The relationship between Joule heating and the $A E$ index for the periods with substorm activity occurring on (a) 31 July 1997 (b) 28 August 1997, and (c) 26 June 1998. Note that the PIXIE data have been included when deriving Joule heating presented here. The solid line in each plot represents the result from the linear regression analyze. report that Joule heating represents by far the largest ionospheric energy sink to the total energy budget. Atmospheric heating can affect thermospheric winds and cause vertical motions which, in turn, change the atmospheric composition. Another possible effect is the expansion of the atmosphere resulting in increasing atmospheric drag on near-Earth satellites (AFSPCPAM15-2, 1997). Even though we usually find Joule heating to be higher than the precipitating electron energy flux, our result strongly indicates that the contribution from auroral particles is more important than that presented in most studies considering the energy budget. This is in accordance with a recent paper by Østgaard et al. (2002b).
They have investigated the energy dissipation rate during 7 substorms from 1997 by using observations from PIXIE and UVI. Nonlinear relations between the energy flux and the $A E$ and $A L$ indices have been established and compared with similar linear relations performed by others. The result by $\emptyset$ stgaard et al. (2002b) is much in accordance with a paper by Lu et al. (1998). However, Østgaard et al. (2002b) find values which are a factor 1-2 times larger than the results by Spiro et al. (1982) and Richmond (1990), and about 4 times larger than reported in studies by Akasofu (1981) and Ahn et al. (1983b). 
Table 1. We present the largest changes in percent of the different electrodynamical parameters when including energetic electrons derived from the PIXIE data during the three events on 31 July 1997, 28 August 1997, and 26 June 1998. The largest changes in the local values of Hall conductance and Joule heating are found in regions of limited extent, as demonstrated in Fig. 2, Fig. 6, Fig. 9, and Fig. 10. We have excluded values less than $10 \mathrm{~S}$ and $10 \mathrm{mWm}^{-2}$, respectively, to avoid effects caused by statistical uncertainties.

\begin{tabular}{lccc}
\hline & \multicolumn{3}{c}{ Largest effects of energetic electrons during the event of: } \\
& 31 July 1997 & 28 August 1997 & 26 June 1998 \\
& 02:00-04:20 UT & 03:00-10:00 UT & 03:00-08:00 UT \\
\hline Local Hall Conductance $\Delta \Sigma_{H}$ & $99 \%$ & $84 \%$ & $138 \%$ \\
Local Joule Heating $\Delta Q_{J}$ & $-39 \%$ & $-47 \%$ & $-58 \%$ \\
Polar Cap Potential Drop $\Delta \Phi_{P C}$ & $-13 \%$ & $-9.2 \%$ & $-12 \%$ \\
Hemispheric Integrated Joule Heating $\Delta Q_{J}$ & $-21 \%$ & $-20 \%$ & $-17 \%$ \\
Hemispheric Integrated Energy Flux $\Delta Q_{A}$ & $8.6 \%$ & $6.7 \%$ & $7.4 \%$ \\
Radio Between Joule Heating and Energy Flux $\left.\Delta Q_{J} / Q_{A}\right)$ & $-27 \%$ & $-25 \%$ & $-22 \%$ \\
\hline
\end{tabular}

In Figs. 5c, 11c and 14c, the ratio between the hemispheric integrated Joule heating $Q_{J}$ and energy flux by precipitating particles $Q_{A}$ is presented. By integrating the total contributions from these two ionospheric energy forms throughout the respective time periods with measurements and then calculating the ratio $Q_{J} / Q_{A}$, we estimate the largest ratio of 1.67 for the severe storm event of 26 June 1998. This value is much larger than the corresponding average ratios of 1.04 and 0.955 for the events of 31 July and 28 August 1997, indicating that the energy flux by the precipitating particles is of special importance for substorm events occurring during non-storm periods or minor geomagnetic storms. It is interesting to note that an inclusion of the neutral wind in the AMIE calculations would probably lead to less Joule heating values and, therefore, even lower ratios between Joule heating and energy flux by precipitating particles. Lu et al. (1995) investigated the effects of neutral wind on Joule heating for 28-29 March 1992, when several intensifications could be seen in the $A E$ index. On the average, for this two-day period, the hemispheric integrated Joule heating was reduced by 28 percent due to the neutral wind.

\section{Conclusion}

In this study we have investigated the effects of energetic electrons on ionospheric electrodynamics. This was done by running the AMIE procedure using UVI and magnetometer data and then investigating energetic electrons by repeating the study and including PIXIE data. We find that the improved spectral characterization of the precipitating electrons using PIXIE data most often results in a larger electron flux at higher energies and consequently, a higher Hall conductance. The increased Hall conductance then leads to a reduction in the estimated electric field, and we find that the calculated polar cap potential drop sometimes decreases by more than $10 \%$ during geomagnetic disturbed periods. This further affects the estimation of Joule heating, which may be $20 \%$ lower on a global scale. In some localized regions, Joule heating can decrease by more than $50 \%$. Including the
PIXIE data increases the energy flux of precipitating particles by approximately $5 \%$, resulting in a decrease in the calculated ratio between Joule heating and energy flux, sometimes by more than $25 \%$. The largest estimated effects of energetic electrons during the three events studied in this paper are presented in Table 1.

We note that the inclusion of the PIXIE data affects the calculation of Hall conductance, polar cap potential, Joule heating and energy flux, while the estimated Pedersen conductance is hardly affected at all.

The relationship between Joule heating and the $A E$ index has also been studied in this paper. In accordance with previous studies, we find a nearly linear relationship between these two quantities. However, our investigation gives proportionality factors between Joule heating and the $A E$ index ranging from 0.13 and $0.23 \mathrm{GW} / \mathrm{nT}$. We suggest that the largest value of $0.23 \mathrm{GW} / \mathrm{nT}$ derived from the event of 26 June 1998, may be attributed to the geomagnetic storm conditions during this day. A more thorough investigation is needed, though, for this proposed relationship, as only three events have been studied in this paper. By comparing our data with the results found by others considering storm and non-storm conditions, respectively, we obtain lower values of the ratio between Joule heating and $A E$ index than reported in previous studies. An investigation has also been performed regarding the relative importance of the ionospheric energy sinks. For the severe storm event of 26 June 1998, the hemispheric integrated Joule heating represents the largest energy form and contributes 1.67 times more than the hemispheric integrated energy flux by precipitating particles. However, corresponding ratios of 1.04 and 0.955 are found for the events of 31 July and 28 August 1997, indicating the importance of the auroral particle precipitation to the energy budget for substorm events occurring during non-storm or minor geomagnetic storm periods.

Acknowledgements. This study was supported by the Research Council of Norway (NFR).

A. Aksnes thanks HAO/NCAR for their hospitality and support during a three-months stay in 2002. 
Work at HAO/NCAR was supported by the NASA SEC Theory program and the SEC Guest Investigator program.

Work at the University of Alabama in Huntsville was supported by Subcontracts SA3527 and SA3216 from the University of California at Berkeley.

The participation of the University of Maryland in this research was supported by Lockheed Martin subcontract SE70A0470.

One of us (A. A.) thanks A. D. Richmond for useful discussions on the AMIE procedure.

The CANOPUS instrument array constructed, maintained and operated by the Canadian Space Agency, provided magnetometer data used in this study. The authors thank I. R. Mann and D. K. Milling for the SAMNET data. SAMNET is a PPARC National Facility deployed and operated by the University of York. The MACCS magnetometer array was provided by Jennifer Posch of Augsburg College. The IMAGE magnetometer array data were provided by Ari Viljanen of the Finnish Meteorological Institute. We thank Jurgen Watermann of the Danish Meteorological Institute for the Greenland magnetometer data. The authors like to acknowledge use of the 210 Magnetic Meridian (MM) data. The PI K. Yumoto manages the $210 \mathrm{MM}$ observations project and group. The database is located at the Solar-Terrestrial Environment Laboratory (STEL) at Nagoya University. The authors thank the following stations and organizations for providing magnetometer data via the INTERMAGNET programme: ABK, and LOV, Geological Survey of Sweden; BEL, Institute of Geophysics, Polish Academy of Sciences; BFE, Danish Meteorological Institute; BLC, CBB, IQA, MEA, OTT, STJ, and VIC, Geological Survey of Canada; BOU, BRW, BSL, CMO, DLR, FRD, FRN, GUA, HON, NEW, SIT, SJG, and TUC, United States Geological Survey; ESK, HAD, and LER, British Geological Survey; FUR, Ludwig Maximilians University Munich; NCK, Geodetic and Geophysical Institute of the Hungarian Academy of Sciences; NGK, and WNG, GeoForschungsZentrum Potsdam; THY, Eotvos Lorand Geohysical Institute of Hungary (Hungarian Geological Survey).

Topical Editor M. Lester thanks R. M. Robinson and another referee for their help in evaluating this paper.

\section{References}

Ahn, B.-H., Robinson, R. M., Kamide, Y., and Akasofu, S.-I.: Electric conductivities, electric fields and auroral particle energy injection rate in the auroral ionosphere and their empirical relations to the horizontal magnetic disturbances, Planet. Space. Sci., 31, 641, 1983a.

Ahn, B.-H., Akasofu, S.-I., and Kamide, Y.: The Joule heat production rate and the particle energy injection rate as a function of the geomagnetic indices $A E$ and $A L$, J. Geophys. Res., 88, 6275, 1983b.

AFSPCPAM15-2: Space Environmental Impacts on DOD Operations, Air Force Space Command Pamphlet 15-2, 53 pp., Air Force Space Command, Peterson AFB, Colorado, 1997.

Aikio, A. T. and Kaila, K. U.: A substorm observed by EISCAT and other ground-based instruments - evidence for near-Earth substorm initiation, J. Atmos. Terr. Phys., 58, 5, 1996.

Aikio, A. T., Opgenoorth, H. J., Persson, M. A. L., and Kaila, K. U.: Ground-based measurements of an arc-associated electric field, J. Atmos. Terres. Phys., 55, 797, 1993.

Akasofu, S.-I.: Energy coupling between the solar wind and the magnetosphere, Space Sci. Rev., 28, 121, 1981.
Aksnes, A., Stadsnes, J., Bjordal, J., Østgaard, N., Vondrak, R. R., Detrick, D. L., Rosenberg, T. J., Germany, G. A., and Chenette, D.: Instantaneous ionospheric global conductance maps during an isolated substorm, Ann. Geophysicae, 20, 1181, 2002.

Baumjohann, W. and Kamide, Y.: Hemispherical Joule heating and the $A E$ indices, J. Geophys. Res., 89, 383, 1984.

Berkey, F. T., Driatskij, V. M., Henriksen, K., Hultqvist, B., Jelly, D., Shchuka, T. I., Theander, A., and Yliniemi, J.: A synoptic investigation of particle precipitation dynamics for 60 substorms in IQSY (1964-65) and IASY (1969), Planet. Space Sci., 22, 255, 1974.

Bostrøm, R.: Electrodynamics of the Ionosphere, in: Cosmical Geophysics, edited by Egeland, A., Holter, Ø. and Omholt, A., Universitetsforlaget, Oslo-Bergen-Troms $\varnothing$, Norway, 1973.

Chapman, S.: The electrical conductivity of the ionosphere: A review, Nuovo Cimento, 4, 1385, 1956.

Cooper, M. L., Clauer, C. R., Emery, B. A., Richmond, A. D., and Winningham, J. D.: A storm time assimilative mapping of ionospheric electrodynamics analysis for the severe geomagnetic storm of November 8-9, 1991, J. Geophys. Res., 100, 19329, 1995.

Creutzberg, F., Gattinger, R. L., Harris, F. R., Wozniak, S., and Vallance Jones, A.: Auroral studies with a chain of meridian scanning photometers, 2, Mean distributions of proton and electron aurora as a function of magnetic activity, J. Geophys. Res., 93, $14591,1988$.

de la Beaujardière, O., Vondrak, R., and Baron, M.: Radar Observations of Electric Fields and Currents Associated With Auroral Arcs, J. Geophys. Res., 82, 5051, 1977.

Evans, D. S., Maynard, N. C., Trøim, J., Jacobsen, T., and Egeland, A.: Auroral Vector Electric Field and Particle Comparisons. 2. Electrodynamics of an Arc, J. Geophys. Res., 82, 2235, 1977.

Foster, J. C., Holt, J. M., Musgrove, R. G., and Evans, D. S.: Ionospheric convection associated with discrete levels of particle precipitation, Geophys. Res. Lett., 13, 656, 1986.

Frey, H. U., Mende, S. B., Carlson, C. W., Gerard, J.-C., Hubert, B., Spann, J., Gladstone, R., and Immel, T. J.: The electron and proton aurora as seen by IMAGE-FUV and FAST, Geophys. Res. Lett., 28, 1135, 2001.

Fuller-Rowell, T. J. and Evans, D. S.: Height-integrated Pedersen and Hall conductivity patterns inferred from the TIROS-NOAA satellite data, J. Geophys. Res., 92, 7606, 1987.

Galand, M., Roble, R. G., and Lummerzheim, D.: Ionization by energetic protons in Thermosphere-Ionosphere Electrodynamics General Circulation Model, J. Geophys. Res., 104, 27 973, 1999.

Galand, M., Fuller-Rowell, T. J., and Codrescu, M. V.: Response of the upper atmosphere to auroral protons, J. Geophys. Res., 106, 127, 2001.

Germany, G. A., Torr, M. R., Richards, P. G., and Torr, D. G.: The dependence of modeled OI 1356 and N2 LBH auroral emissions on the neutral atmosphere, J. Geophys. Res., 95, 7725, 1990.

Germany, G. A., Parks, G. K., Brittnacher, M., Cumnock, J., Lummerzheim, D., Spann, J. F., Chen, L., Richards, P. G., and Rich, F. J.: Remote determination of auroral energy characteristics during substorm activity, Geophys. Res. Lett., 24, 995, 1997.

Germany, G. A., Parks, G. K., Brittnacher, M., Spann, J. F., Cumnock, J., Lummerzheim, D., Rich, F. J., and Richards, P. G.: Energy characterization of a dynamic auroral event using GGS UVI images, in: Geospace Mass and Energy Flow: Results from the International Solar-Terrestrial Physics Program, edited by Horwitz, J. L., Gallagher, D. L., and Peterson, W. K., pp. 143, AGU, 104, Washington, D.C., 1998a. 
Germany, G. A., Spann, J. F., Parks, G. K., Brittnacher, M., Elsen, R., Chen, L., Lummerzheim, D., and Rees, M.: Auroral observations from the Polar Ultraviolet Imager (UVI), in: Geospace Mass and Energy Flow: Results from the International SolarTerrestrial Physics Program, edited by Horwitz, J. L., Gallagher, D. L., and Peterson, W. K., pp. 149, AGU, 104, Washington, D.C., 1998 b.

Germany, G. A., Lummerzheim, D., and Richards, P. G.: Impact of model differences on quantitative analysis of FUV auroral emissions: Total ionization cross sections, J. Geophys. Res., 106, 12837,2001

Gjerloev, J. W. and Hoffman, R. A.: Height-integrated conductivity in auroral substorms. 1. Data, J. Geophys. Res., 105, 215, 2000.

Gledhill, J. A.: The effective recombination coefficient of electrons in the ionosphere between 50 and $150 \mathrm{~km}$, Radio Sci., 21, 3, 339, 1986.

Goldberg, R. A., Barcus, J. R., Treinish, L. A., and Vondrak, R. R.: Mapping of auroral X rays from rocket overflights, J. Geophys. Res., 87, 2509, 1982.

Gonzalez, W. D., Joselyn, J. A., Kamide, Y., Kroehl, H. W., Rostoker, G., Tsurutani, B. T., and Vasyliunas, V. M.: What is a geomagnetic storm?, J. Geophys. Res., 99, 5771, 1994.

Harel, M., Wolf, R. A., Spiro, R. W., Reiff, P. H., Chen, C.-K., Burke, W. J., Rich, F. J., and Smiddy, M.: Quantitative simulation of a magnetospheric substorm, J. Geophys. Res., 86, 2242, 1981.

Hardy, D. A., Gussenhoven, M. S., and Holemann, E.: A statistical model of auroral electron precipitation, J. Geophys. Res., 90, 4229, 1985

Hardy, D. A., Gussenhoven, M. S., Vaistrick, R., and McNeil, W. J.: Statistical and functional representations of the pattern of auroral energy flux, number flux, and conductivity, J. Geophys. Res., 92, $12275,1987$.

Hardy, D. A., Gussenhoven, M. S., and Brautigam, D.: A statistical model of auroral ion precipitation, J. Geophys. Res., 94, 370, 1989.

Hardy, D. A., McNeil, W., Gussenhoven, M. S., and Brautigam, D.: A statistical model of auroral ion precipitation, 2, Functional representation of the average patterns, J. Geophys. Res., 96, 5539, 1991.

Hartz, T. R. and Brice, N. M.: The general pattern of auroral particle precipitation, Planet. Space Sci., 15, 301, 1967.

Imhof, W. L., Spear, K. A., Hamilton, J. W., Higgins, B. R., Murphy, M. J., Pronko, J. G., Vondrak, R. R., McKenzie, D. L., Rice, C. J., Gorney, D. J., Roux, D. A., Williams, R. L., Stein, J. A., Bjordal, J., Stadsnes, J., Njoten, K., Rosenberg, T. J., Lutz, L., and Detrick, D. L.: The Polar Ionospheric X-ray Imaging Experiment (PIXIE), Space Sci. Rev., 71, 385, 1995.

Jelly, D. and Brice, N.: Changes in Van Allen radiation associated with polar substorms, J. Geophys. Res., 72, 5919, 1967.

Johnson, M. L., Murphree, J. S., Marklund, G. T., and Karlsson, T.: Progress on relating optical auroral forms and electric field patterns, J. Geophys. Res., 103, 4271, 1998.

Kamide, Y., Richmond, A. D., and Matsushita, S.: Estimation of ionospheric electric fields, ionospheric currents, and fieldaligned currents from ground magnetic records, J. Geophys. Res., 86, 801, 1981.

Kamide, Y., Ahn, B.-H., Akasofu, S.-I., Baumjohann, W., FriisChristensen, E., Kroehl, H. W., Maurer, H., Richmond, A. D., Rostoker, G., Spiro, R. W., Walker, J. K., and Zaitzev, A. N.: Global distribution of ionospheric and field-aligned currents during substorms as determined from six IMS meridian chains of magnetometers: Initial results, J. Geophys. Res., 87, 8228, 1982.

Kangas, J., Lukkari, L., Tanskanen, P., Trefall, H., Stadsnes, J., Kremser, G., and Riedler, W.: On the morphology of auroralzone X-ray events-IV. Substorm-related electron precipitation in the local morning sector, J. Atmos. Terr. Phys., 37, 1289, 1975.

Kirkwood, S., Opgenoorth, H., and Murphree, J. S.: Ionospheric conductivities, electric fields and currents associated with auroral substorms measured by the EISCAT radar, Planet. Space. Sci., 36, 1359, 1988

Knipp, D. J., Emery, B. A., Engebretson, M., Li, X., McAllister, A. H., Mukai, T., Kokubun, S., Reeves, G. D., Evans, D., Obara, T., Pi, X., Rosenberg, T., Weatherwax, A., McHarg, M. G et al.: An overview of the early November 1993 geomagnetic storm, J. Geophys. Res., 103, 26 197, 1998.

Lanchester, B. S., Kaila, K., and McCrea, I. W.: Relationship between large horizontal electric fields and auroral arc elements, J. Geophys. Res., 101, 5075, 1996.

Lorence, L. J.: CEPXS/ONELD Version 2.0: A discrete ordinates code package for general one-dimensional coupled electronphoton transport, IEES Trans. Nucl. Sci, 39, 1031, 1992.

Lu, G., Richmond, A. D., Emery, B. A., and Roble, R. G.: Magnetosphere-ionosphere-thermosphere coupling: Effect on neutral winds on energy transfer and field-aligned current, J. Geophys. Res., 100, 19643, 1995.

Lu, G., Emery, B. A., Rodger, A. S., Lester, M., Taylor, J. R., Evans, D. S., Ruohoniemi, J. M., Denig, W. F., et al.: High-latitude ionospheric electrodynamics as determined by the assimilative mapping of ionospheric electrodynamics procedure for the conjunctive SUNDIAL/ATLAS 1/GEM period of March 28-29, 1992, J. Geophys. Res., 101, 26 697, 1996.

Lu, G., Baker, D. N., McPherron, R. L., Farrugia, C. J., Lummerzheim, D., Ruohoniemi, J. M., Rich, F. J., Evans, D. S., Lepping, R.P., et al.: Global energy deposition during the January 1997 magnetic cloud event, J. Geophys. Res., 103, 11 685, 1998.

Lummerzheim, D., Rees, M. H., Craven, J. D., and Frank, L. A.: Ionosheric conductances derived from DE-1 auroral images, J. Atmos. Terr. Phys., 53, 281, 1991.

Marklund, G., Sandahl, I., and Opgenoorth, H.: A study of the dynamics of a discrete auroral arc, Planet. Space Sci., 30, 179, 1982.

McDiarmid, I. B., Burrows, J. R., and Budzinski, E. E.: Average characteristisc of magnetospheric electrons $(150 \mathrm{eV}$ to $200 \mathrm{keV})$ at $1400 \mathrm{~km}$, J. Geophys. Res., 80, 73, 1975.

Meng, C. -I., Mauk, B., and McIlwain, C. E.: Electron precipitation of evening diffuse aurora and its conjugate electron fluxes near the magnetospheric equator, J. Geophys. Res., 84, 2545, 1979.

Miller, K. L. and Vondrak, R. R.: A high-latitude phenomenological model of auroral precipitation and ionospheric effects, Radio Sci., 20, 3, 431, 1985.

Morelli, J. P., Bunting, R. J., Cowley, S. W. H., Farrugia, C. J., Freeman, M. P., Friis-Christensen, E., Jones, G. O. L., Lester, M., Lewis, R. V., Lühr, H., Orr, D., Pinnock, M., Reeves, G. D., Williams, P. J. S., and Yeoman, T. K.: Radar observations of auroral zone flows during a multiple-onset substorm, Ann. Geophysicae, 13, 1144, 1995.

Newell, P. T., Burke, W. J., Meng, C.-I., Sanchez, E. R., and Greenspan, M. E.: Identification and observations of the plasma mantle at low altitude, J. Geophys. Res., 96, 35, 1991.

Opgenoorth, H. J., Haggstrøm, I., Williams, P. J. S., and Jones, G. O. L.: Regions of strongly enhanced perpendicular electric fields adjacent to auroral arcs, J. Atmos. Terres. Phys., 52, 449, 1990.

Østgaard, N., Stadsnes, J., Bjordal, J., Vondrak, R. R., Cummer, S. 
A., Chenette, D., Parks, G. K., Brittnacher, M. J., and McKenzie, D. L.: Global-scale electron precipitation features seen in UV and X rays during substorms, J. Geophys. Res., 104, 10191 , 1999.

Østgaard, N., Stadsnes, J., Bjordal, J., Vondrak, R. R., Cummer, S. A., Chenette, D., Schulz, M., and Pronko, J.: Cause of the localized maximum of X-ray emission in the morning sector: A comparison with electron measurements, J. Geophys. Res., 105, 20869, 2000.

Østgaard, N., Stadsnes, J., Bjordal, J., Germany, G. A., Vondrak, R. R., Parks, G. K., Cummer, S. A., Chenette, D., and Pronko, J.: Auroral electron distributions derived from combined UV and X-ray emissions, J. Geophys. Res., 106, 26 081, 2001.

Østgaard, N., Germany, G. A., Stadsnes, J., and Vondrak, R. R.: Energy analysis of substorms based on remote sensing techniques, solar wind measurements and geomagnetic indices, J. Geophys. Res., 107, 1233, 2002a.

Østgaard, N., Vondrak, R. R., Gjerloev, J. M., and Germany, G. A.: A relation between the energy deposition by electron precipitation and geomagnetic indices during substorms, J. Geophys. Res., 107, 1246, $2002 b$.

Rees, M. H.: Auroral ionization and excitation by incident energetic electrons, Planet. Space. Sci., 11, 1209, 1963.

Rees, M. H.: On the interaction of auroral protons with the Earth's atmosphere, Planet. Space. Sci., 30, 463, 1982.

Richmond, A. D.: Assimilative mapping of ionospheric electrodynamics, Adv. Space Res., 6(6), 59, 1992.

Richmond, A. D.: Ionospheric electrodynamics using magnetic apex coordinates, J. Geomagn. Geoelectr., 47, 191, 1995.

Richmond, A. D. and Kamide, Y.: Mapping electrodynamic features of the high-latitude ionosphere from localized observations: Technique, J. Geophys. Res., 93, 5741, 1988.

Richmond, A. D., Kamide, Y., Akasofu, S.-I., Alcaydé, D., Blanc, M., de la Beaujardière, O., Evans, D. S., Foster, J. C., FriisChristensen, E., Holt, J. M., Pellinen, R. J., Senior, C., and Zaitzev, A. N.: Global measures of ionospheric electrodynamic activity inferred from combined incoherent scatter radar and ground magnetometer observations, J. Geophys. Res., 95, 1061, 1990.

Richmond, A. D., Ridley, E. C., and Roble, R. G.: A thermosphere/ionosphere general circulation model with coupled electrodynamics, Geophys. Res. Lett., 19, 601, 1992.

Robinson, R. M., Vondrak, R. R., Miller, K., Dabbs, T., and Hardy, D.: On calculating ionospheric conductances from the flux and energy of precipitating electrons, J. Geophys. Res., 92, 2565, 1987.
Schlegel, K.: Auroral zone E-region conductivities during solar minimum derived from EISCAT data, Ann. Geophysicae, 6, 129, 1988.

Shue, J.-H. and Weimer, D. R.: The relationship between ionospheric convection and magnetic activity, J. Geophys. Res., 99, 401, 1994.

Sletten, A., Stadsnes, J., and Trefall, H.: Auroral-zone X-ray events and their relation to polar magnetic substorms, J. Atmos. Terres. Phys., 33, 589, 1971.

Spiro, R. W., Reiff, P. H., and Maher, Jr., L. J.: Precipitating electron energy flux and auroral zone conductances - an empirical model, J. Geophys. Res., 87, 8215, 1982.

Stern, D. P.: Energetics of the magnetosphere, Space Sci. Rev., 39, 193, 1984.

Thrane, E. V. and Piggott, W. R.: The collision frequency in the E- and D-regions of the ionosphere, J. Atmos. Terres. Phys., 28, 721, 1966.

Torr, M. R., Torr, D. G., Zukic, M., Johnson, R. B., Ajello, J., Banks, P.: A far ultaviolet imager for the international solarterrestrial physics mission, Space Sci. Rev., 71, 329, 1995.

Tsurutani, B. T. and Gonzalez, W.: The efficiency of "viscous interaction" between the solar wind and the magnetosphere during intense northward IMF events, Geophys. Res. Lett., 22, 663, 1995.

VanZandt, T. E., Clark, W. L., and Warnock, J. M.: Magnetic apex coordinates: A magnetic coordinate system for the ionospheric F2-layer, J. Geophys. Res., 77, 2406, 1972.

Vickrey, J. F., Vondrak, R. R., and Matthews, S. J.: The diurnal and latitudinal variation of auroral zone ionospheric conductivity, J. Geophys. Res., 86, 65, 1981.

Vickrey, J. F., Vondrak, R. R., and Matthews, S. J.: Energy depostion by energetic particles and Joule dissipation in the auroral ionosphere, J. Geophys. Res., 87, 5184, 1982.

Vondrak, R. R. and Robinson, R.: Inference of high-latitude ionization and conductivity from $A E-\mathrm{C}$ measurements of auroral electron fluxes, J. Geophys. Res., 90, 7505, 1985.

Vondrak, R. R. and Baron, M. J.: Radar measurements of the latitudinal variation of auroral ionization, Radio Sci., 11, 939, 1976.

Wallis, D. D. and Budzinski, E. E.: Empirical models of height integrated conductivities, J. Geophys. Res., 86, 125, 1981.

Wentworth, E. P.: Rocket Measurements of Auroral Electric and Magnetic Fields, J. Geophys. Res., 75, 5415, 1970.

Wescott, E., Stolarik, J. D., and Heppner, J. P.: Electric Fields in the Vicinity of Auroral Forms from Motions of Barium Vapor Releases, J. Geophys. Res., 74, 3469, 1969. 